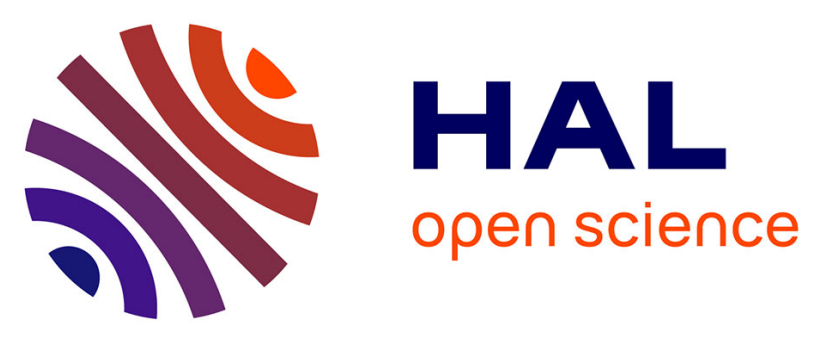

\title{
Modeling the Acid-Base Properties of Montmorillonite Edge Surfaces
}

\author{
Christophe Tournassat, James A Davis, Christophe C Chiaberge, Sylvain \\ Grangeon, Ian C. Bourg
}

\section{To cite this version:}

Christophe Tournassat, James A Davis, Christophe C Chiaberge, Sylvain Grangeon, Ian C. Bourg. Modeling the Acid-Base Properties of Montmorillonite Edge Surfaces. Environmental Science and Technology, 2016, 50 (24), pp.13436-13445. 10.1021/acs.est.6b04677 . insu-01415340

\section{HAL Id: insu-01415340 \\ https://hal-insu.archives-ouvertes.fr/insu-01415340}

Submitted on 13 Dec 2016

HAL is a multi-disciplinary open access archive for the deposit and dissemination of scientific research documents, whether they are published or not. The documents may come from teaching and research institutions in France or abroad, or from public or private research centers.
L'archive ouverte pluridisciplinaire HAL, est destinée au dépôt et à la diffusion de documents scientifiques de niveau recherche, publiés ou non, émanant des établissements d'enseignement et de recherche français ou étrangers, des laboratoires publics ou privés.

\section{(1) (1) $\$$}

Distributed under a Creative Commons Attribution - NonCommercial - NoDerivatives| 4.0 


\section{Modeling the acid-base properties of montmorillonite edge surfaces}

2 Christophe Tournassat ${ }^{\mathrm{a}, \mathrm{b}, \mathrm{c}^{*}}$, James A. Davis $^{\mathrm{b}}$, Christophe Chiaberge ${ }^{\mathrm{c}}$, Sylvain Grangeon ${ }^{\mathrm{c}}$, Ian C.

5 a Université d'Orléans - CNRS/INSU - BRGM, UMR 7327 Institut des Sciences de la Terre

6 d'Orléans, 45071 Orléans, France

$7 \quad{ }^{\mathrm{b}}$ Earth and Environmental Sciences Division, Lawrence Berkeley National Laboratory, Berkeley, 8 USA

$9{ }^{\mathrm{c}}$ BRGM, French geological Survey, Orléans, France

$10 \mathrm{~d}$ Department of Civil and Environmental Engineering and Princeton Environmental Institute,

11 Princeton, USA

$12 *$ corresponding author: c.tournassat@brgm.fr

13 


\section{Abstract}

15 The surface reactivity of clay minerals remains challenging to characterize because of a duality of

16 adsorption surfaces and mechanisms that does not exist in the case of simple oxide surfaces: clay

17 minerals edge surfaces have a variable proton surface charge arising from hydroxyl functional

18 groups, whereas basal surfaces have a permanent negative charge arising from isomorphic

19 substitutions. Hence, the relationship between surface charge and surface potential on edge

20 surfaces cannot be described using the Gouy-Chapman relation, because of a spillover of

21 negative electrostatic potential from the basal surface onto the edge surface. While surface

22 complexation models can be modified to account for these features, a predictive fit of

23 experimental data was not possible until recently, because of uncertainty regarding the densities

24 and intrinsic $\mathrm{p} K_{\mathrm{a}}$ values of edge functional groups. Here, we reexamine this problem in light of

25 new knowledge on intrinsic $\mathrm{p} K_{\mathrm{a}}$ values obtained over the last decade using ab initio molecular

26 dynamics simulations, and we propose a new formalism to describe edge functional groups. Our

27 simulation results yield good predictions of the best available experimental acid-base titration 28 data.

\section{1. Introduction}

30 Clay minerals are natural fine-grained particles, ubiquitous in terrestrial weathering

31 environments, that strongly influence the permeability, mechanics, and pore water chemistry of

32 soils, sediments, and rocks in which they are found ${ }^{1,2}$. In particular, these minerals control the

33 performance of natural and engineered clay barriers used in the isolation of landfills and

34 contaminated sites and proposed for use in the geological storage of high-level radioactive waste

$35 \quad 3,4$. A widely examined feature of clay minerals that influences the performance of these barriers 
36 is their cation-exchange capacity, the result of isomorphic substitutions in the structure ${ }^{5}$. In

37 addition to this cation-exchange capacity, clay minerals, including montmorillonite (the most 38 studied swelling clay mineral) carry oxide-type functional groups on their edge surfaces. These

39 oxide-type functional groups, though present in much smaller quantity than the cation exchange

40 sites, dominate the adsorption of trace metals, oxyanions, and organic molecules ${ }^{6-9}$, the

41 dissolution and growth kinetics of clay minerals ${ }^{10,11}$, and the colloidal mechanics of clay

42 particles ${ }^{12}$, at least in some conditions.

43 In the case of simple oxide minerals, surface reactivity is strongly influenced by their net proton

44 surface charge, which varies with $\mathrm{pH}$ through reactions of the following type, where $>\mathrm{SOH}_{\mathrm{n}}$ is a

45 generic surface site ${ }^{13}$ :

$$
>\mathrm{SOH}_{n} \rightleftarrows>\mathrm{SOH}_{n-1}+\mathrm{H}^{+}
$$

46 The reaction described by Eq. (1) gives rise to a variable net proton surface charge density $\left(\sigma_{H}\right)$

47 that depends on $\mathrm{pH}$ and ionic strength $\left(I\right.$, dimensionless $\left.{ }^{14}\right)$. In the case of simple oxide minerals,

48 the last few decades have seen steady advances in the characterization of their proton surface

49 chemistry through a combination of experiments (in particular, acid-base titration and

50 electrophoretic mobility measurements), surface complexation model (SCM) calculations, and

51 bond-valence theory predictions of the intrinsic acidity constants of surface functional groups ${ }^{15-}$

5219 . In the case of the oxide-type functional groups on the montmorillonite edge surfaces, however,

$53 \sigma_{\mathrm{H}}$ remains poorly understood, as shown by the wide range of reported values of the point of zero

54 net proton charge (p.z.n.p.c., the $\mathrm{pH}$ value where $\sigma_{\mathrm{H}}=0$ ) and by the variety of models that have

55 been used to describe $\sigma_{\mathrm{H}}{ }^{9,20}$. As described below, the difficulty in characterizing $\sigma_{\mathrm{H}}$ on

56 montmorillonite relates to the high permanent structural charge of the solid $\left(\sigma_{0} \approx-1 \mathrm{mmol}_{\mathrm{c}} \cdot \mathrm{g}^{-1}\right)$ 
57 and to the presence of two different surfaces (edge and basal surfaces) with very different

58 properties. These properties have no equivalent in simple oxide minerals, but are widespread

59 features of lamellar structures including vernadite, a phyllomanganate that controls the fate of

60 trace metals in certain oxidized soils and sediments ${ }^{21,22}$, green rust, a layered double hydroxide

61 that influences the mobility of iron and anions in reduced soils ${ }^{23}$, and synthetic phases widely

62 used in materials chemistry, such as synthetic layered double hydroxides ${ }^{24}$.

63 The challenges associated with characterizing the proton surface reactivity of montmorillonite

64 were summarized a decade ago by Bourg et al. ${ }^{20}$. A first challenge is that montmorillonite

65 particles undergo significant dissolution during acid-base titration measurements. This can be

66 rendered near-negligible in the $\mathrm{pH}$ range from about 4.5 to 9.5 through a careful choice of clay

67 pretreatment, storage, and titration procedures $^{25-29}$ (see below). Unfortunately, most

68 montmorillonite acid-base titration datasets do not fit the best practices established by Duc et al.

$6^{25-28}$. A second challenge is that acid-base titration measurements do not directly measure the net

70 proton surface charge density $\sigma_{\mathrm{H}}$ but rather $\delta \sigma_{\mathrm{H}}$, the change in net proton surface charge density

71 relative to its initial value $\sigma_{\mathrm{H} \text {,init }}\left(\delta \sigma_{\mathrm{H}}=\sigma_{\mathrm{H}}-\sigma_{\mathrm{H} \text {,init }}\right)$. Conversion of $\delta \sigma_{\mathrm{H}}$ to $\sigma_{\mathrm{H}}$ values requires

72 knowledge of $\sigma_{\mathrm{H} \text {,init }}$ or of the p.z.n.p.c. at the conditions of interest ${ }^{30}$. For simple oxide surfaces,

73 this is achieved by measuring the sum of the adsorbed ion charge densities $q_{i}$ of all species except

$74 \mathrm{H}^{+}$and $\mathrm{OH}^{-}(\Delta q)$ and applying the charge balance relation ${ }^{30}$ :

$$
\sigma_{0}+\sigma_{\mathrm{H}}+\Delta q=0
$$

75 For montmorillonite, experimental uncertainties make it impossible to accurately determine $\sigma_{\mathrm{H}}$

76 using Eq. (2), because $\sigma_{\mathrm{H}}$ is small compared to $\sigma_{0}$ and $\Delta q^{20,29}$. Alternatively, the p.z.n.p.c. of

77 oxide surfaces is sometimes determined by assuming that it coincides with the point of zero salt 
78 effect (p.z.s.e., the $\mathrm{pH}$ value at which acid-base titration curves carried out at different ionic

79 strengths intersect) or with the isoelectric point (i.e.p., the $\mathrm{pH}$ value where the electrophoretic

80 mobility equals zero) ${ }^{31}$. These alternative methods, however, are neither strictly rigorous ${ }^{20,30}$ nor

81 applicable to montmorillonite, for which a p.z.s.e. or i.e.p. are not observed ${ }^{26,32-34}$. Finally, the

82 p.z.n.p.c. of montmorillonite is sometimes assumed to correspond to the $\mathrm{pH}$ value obtained by

83 adding incremental amounts of dry solid to a solution ${ }^{35}$, but this so-called "mass titration"

84 technique, just like a standard acid-base titration, is sensitive to the initial protonation state of the 85 solid $^{36}$.

86 A third challenge arises when attempting to develop a SCM for montmorillonite. An important 87 assumption of SCMs is that the ratio of activity coefficients of different surface species is a 88 function of the surface electrostatic potential $\psi$. For the reaction described by Eq. (1), the 89 relationship is almost always expressed with a quasi-thermodynamic equilibrium equation of the 90 form:

$$
K_{\mathrm{a}}=\frac{\left[>\mathrm{SOH}_{n-1}\right]\left(\mathrm{H}^{+}\right)}{\left[>\mathrm{SOH}_{n}\right]} \exp \left(\frac{-F \psi}{R T}\right)
$$

91 where $K_{\mathrm{a}}$ is an intrinsic equilibrium constant, $\left(\mathrm{H}^{+}\right)$is the thermodynamic activity of $\mathrm{H}^{+}$, square

92 brackets denote mole fractions, $\psi$ is the surface electrostatic potential, $F$ is the Faraday constant 93 (96 $\left.485 \mathrm{C} \mathrm{mol}^{-1}\right), R$ is the ideal gas constant $\left(8.314 \mathrm{~J} \mathrm{~mol}^{-1} \mathrm{~K}^{-1}\right)$, and $T$ is temperature (in $\mathrm{K}$ ).

94 Closure of any SCM requires a model of $\psi$ as a function of surface charge, ionic strength, and 95 other conditions. For this, most studies rely on the Gouy-Chapman relation, a mean-field theory 96 prediction based on the Poisson-Boltzmann equation (PBE) of the relationship between surface 97 charge density and surface potential on an infinite planar surface in contact with an ideal 98 electrolyte solution ${ }^{31,37}$. Montmorillonite consists of flake-shaped, 1-nm-thick layers such that 
99 the narrow edge surface cannot be a priori treated as an infinite planar surface ${ }^{9,20}$. Solutions to

100 the Poisson-Boltzmann equation for various possible arrangements of the montmorillonite layers

101 indicate that the value of $\psi$ at montmorillonite edges ( $\psi$ edge $)$ is influenced by the charge density

102 of both edge and basal surfaces in a manner that depends on ionic strength and on the stacking

103 arrangement of montmorillonite layers ${ }^{9,20,38}$. Finally, a fourth challenge is that montmorillonite

104 edge surfaces carry a variety of functional groups associated with tetrahedral Si and octahedral Al

105 atoms $\left(>\mathrm{SiOH},>\mathrm{AlOH},>\mathrm{Al}_{2} \mathrm{OH},>\mathrm{AlSiOH}\right)$ as well as additional groups that arise from

106 isomorphic substitutions of $\mathrm{Si}$ by $\mathrm{Al}$ and of $\mathrm{Al}$ by $\mathrm{Mg}, \mathrm{Fe}^{\mathrm{II}}$, or $\mathrm{Fe}^{\mathrm{III}}$. In the absence of independent

107 predictions of the densities and intrinsic acidity constants of each surface functional group, model

108 fits to experimental acid-base titration data are necessarily non-unique ${ }^{20}$.

109 Bourg et al. ${ }^{20}$ showed that the first three challenges outlined above could be resolved using

110 information available a decade ago. The second challenge was resolved by using an SCM to

111 predict both $\sigma_{\mathrm{H}, \text { init }}$ (from reported conditions of clay pre-treatment) and $\sigma_{\mathrm{H}}$. The first challenge

112 required identifying experimental datasets that followed that best practices established by Duc et

113 al. ${ }^{26-28}$ and that used montmorillonite samples pre-treated by repeated washing in a solution of

114 well-known $\mathrm{pH}$ and ionic strength (as required to predict $\sigma_{\mathrm{H}, \text { init }}$ ); the available database included

115 only two datasets, those of Baeyens and Bradbury ${ }^{39}$ and Duc et al. ${ }^{27}$. The third challenge was

116 resolved by solving a two-dimensional version of the PBE near the edge surface of an isolated

117 montmorillonite particle. The fourth challenge, however, could not be satisfactorily resolved,

118 because of large disagreements between different bond-valence model predictions of the intrinsic

$119 \mathrm{p} K_{\mathrm{a}}$ values of edge surface sites ${ }^{40,41}$ and, also, because of insufficient knowledge of the densities

120 of different edge surface sites ${ }^{41}$. Eventually, Bourg et al. ${ }^{20}$ concluded that experimental data on 
121 the acid-base chemistry of montmorillonite edge surfaces could not be predicted from first

122 principles using existing knowledge.

123 The last decade has seen a significant number of new studies of the acid-base surface chemistry

124 of montmorillonite. Several new potentiometric titration studies have been carried out ${ }^{42-47}$ as

125 well as one study that attempted to determine the i.e.p. of montmorillonite edge surfaces ${ }^{48}$.

126 Several studies have provided new estimates of the edge specific surface area of montmorillonite

127 particles ${ }^{10,49}$. Models of $\psi_{\text {edge }}$ have been refined using new Poisson-Boltzmann calculations ${ }^{9}$ and

128 Grand Canonical Monte Carlo (GCMC) simulations ${ }^{50}$. Finally, ab initio MD simulations have

129 been used to predict the intrinsic $\mathrm{p} K_{\mathrm{a}}$ values of montmorillonite edge surface sites ${ }^{51-57}$. Here, we

130 revisit the conclusions of Bourg et al. ${ }^{20}$ in light of these advances. First, we show that new

131 knowledge obtained during the last decade provides a more coherent picture of the proton surface

132 chemistry of montmorillonite. Then, we develop a state-of-the-art SCM for montmorillonite edge

133 surfaces, and we note possibilities for future improvements. This new SCM is mainly based on a

134 combination of the existing 2D Poisson-Boltzmann calculations, which are representative of clay

135 edges geometry, with the development of a revised thermodynamic concept for the description of

136 the edge sites, and with the use of $\mathrm{p} K_{\mathrm{a}}$ values that have been obtained from ab initio MD

137 simulations.

138 2. Constraints on the proton surface chemistry of montmorillonite edges

\section{2.1. Montmorillonite edge structure}

140 Current knowledge of the densities of different types of montmorillonite edge functional groups

141 remains limited by uncertainty regarding edge crystallographic orientations. Crystal growth

142 theory calculations, surface Coulomb energy considerations, atomistic simulations, and in situ 
143 observation of dissolution kinetics using atomic force microscopy suggest the that most stable

144 edge surfaces are perpendicular to [010] and [110] (or, equivalently, [110]) ${ }^{58-63}$, where the Miller

145 indices are assigned according to Churakov ${ }^{60}$ (Figure 1). The two edge surfaces are sometimes

146 referred to as the $\mathrm{B}$ and $\mathrm{AC}$ edges, respectively, following the seminal study by White and

147 Zelazny ${ }^{63}$. Recent molecular dynamics (MD) and ab initio MD simulations of hydrated clay

148 edges suggest that the surface normal to [110] may be significantly more stable than the surface

149 normal to [010] in the presence of liquid water ${ }^{61,62,64}$.

150 Montmorillonite edge surfaces are routinely assumed to have the same stoichiometry and

151 structure as the bulk crystal, with minor bond-length relaxation to accommodate over- or under-

152 coordinated surface $\mathrm{O}$ atoms ${ }^{40}$. Recent $\mathrm{MD}$ and $a b$ initio $\mathrm{MD}$ simulation results reveal a more

153 complex picture, the most well-established finding being that cations in the octahedral layer can

154 adopt a five-fold coordination ${ }^{55,61,65,66}$. 

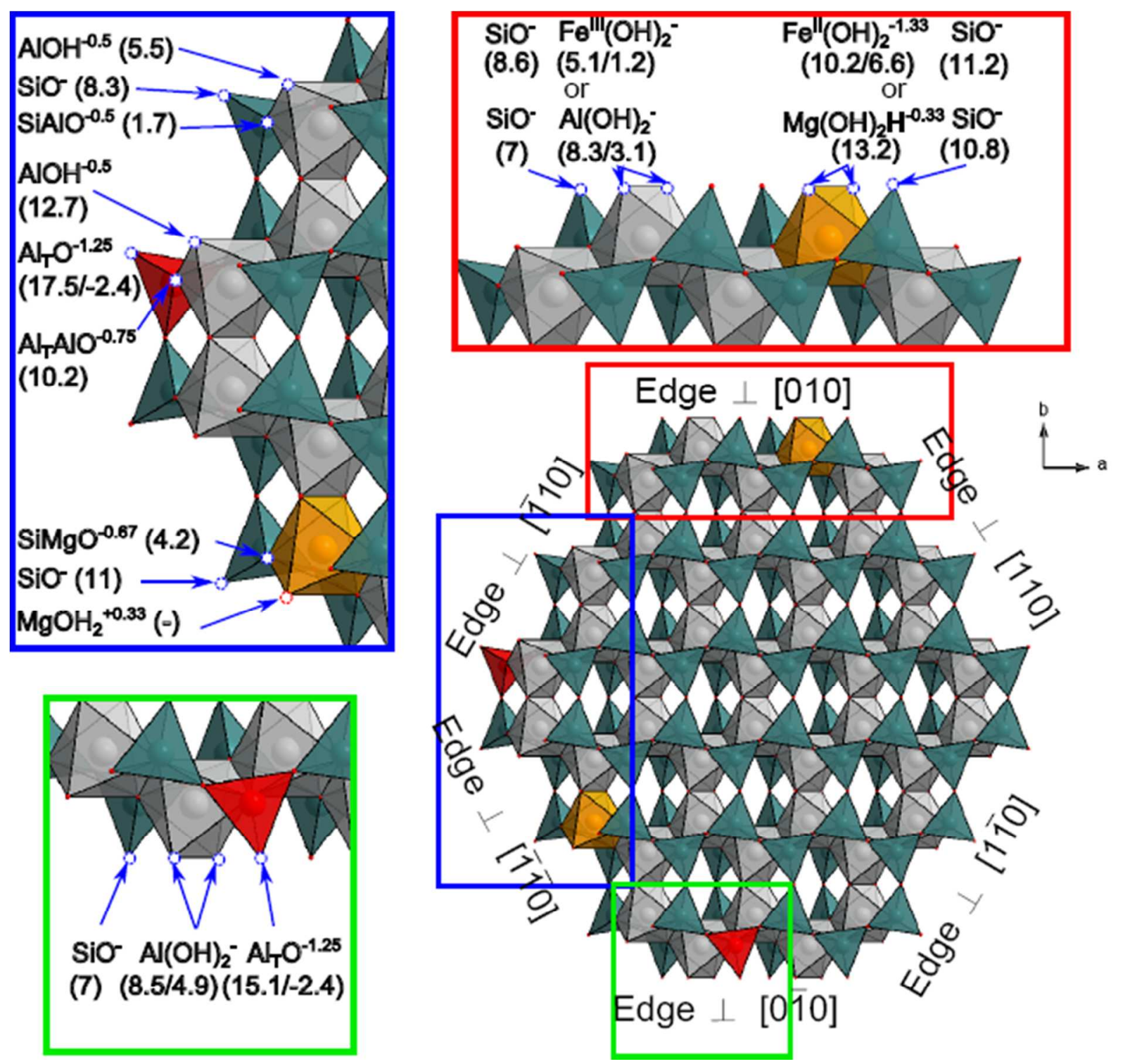

156 Figure 1. Edge surface sites of a model montmorillonite particle. Inserts with red and green

157 borders describe sites on the $\mathrm{B}$ edge. The insert with a blue border describes sites on the AC

158 edge. The clay mineral structure was taken from Viani et al. ${ }^{67}$ and is representative of the

159 structures considered in bond valence calculations and ab initio MD simulations. Grey octahedra:

$160 \mathrm{Al}$ or $\mathrm{Fe}(\mathrm{III})$; orange octahedra: $\mathrm{Mg}$ or $\mathrm{Fe}(\mathrm{II})$; green tetrahedra: Si; red tetrahedra: Al. Isomorphic

161 substitutions are only shown if they occur at the edge surface. The stoichoimetries of the

162 deprotonated sites are written on the figure along with numbers corresponding to the $\log K$ values 
163 of the associated protonation reactions predicted by ab initio MD calculations (see Section 2.4; an

164 absence of value means that the site does not protonate/deprotonate in the $\mathrm{pH}$ range 1 to 14).

\subsection{Edge specific surface area}

167 An important parameter in studies of montmorillonite edge reactivity is the edge specific surface 168 area, $a_{\mathrm{s} \text {,edge. }}$ Unfortunately, the $\mathrm{N}_{2}$ gas adsorption method with the Brunauer-Emmett-Teller 169 technique $\left(\mathrm{N}_{2}\right.$-BET) quantifies only the external surface area of crystals (stacks of

170 montmorillonite layers) after drying, which provides no information on $a_{\text {s,edge }}{ }^{68}$. The ethylene 171 glycol monoethyl ether (EGME) adsorption method quantifies the total specific surface area of 172 montmorillonite layers, $a_{\mathrm{s}}$, dominated by the basal surfaces ${ }^{69}$. In principle, $a_{\mathrm{s}, \text { edge }}$ equals the

173 difference between the measured $a_{\mathrm{s}}$ value and the theoretical basal specific surface area $a_{\text {s,basal }}[\approx$ 174750 to $\left.780 \mathrm{~m}^{2} \mathrm{~g}^{-1} 70\right]$. Unfortunately, EGME-derived $a_{\mathrm{s}}$ values show a significant dependence on 175 experimental conditions ${ }^{68}$ that precludes a precise calculation of $a_{\text {s,edge }}$.

176 Direct measurements of $a_{\mathrm{s}, \text { edge }}$ for montmorillonite have been achieved using two approaches.

177 The first consists in evaluating edge specific surface area by statistical analysis of particle 178 morphology from atomic force microscopy (AFM) or transmission electron microscopy (TEM)

179 images ${ }^{71-73}$. Alternatively, the derivative isotherms summation (DIS) method distinguishes 180 different clay surfaces in a single gas adsorption measurement based on differences in adsorption 181 energy ${ }^{68}$. Comparison of microscopic imaging and DIS results yields satisfactory agreement 182 (Table S-1), with a possible slight overestimation of edge surface area by the DIS method ${ }^{74}$ 


\subsection{Edge surface electrostatic potential}

184 As noted above, SCMs of proton adsorption on montmorillonite require a model of the edge

185 surface electrostatic potential, $\psi_{\text {edge. }}$ Most modeling studies have assumed that clay edges do not

186 develop a significant electrostatic potential $\left(\psi_{\text {edge }}=0\right)^{41,75-79}$ or that $\psi_{\text {edge }}$ follows the Gouy-

187 Chapman relation for an infinite planar surface ${ }^{33,35,43,80-91}$. The few studies that solved the PBE

188 near clay edges for realistic geometries, however, showed that $\psi_{\text {edge }}$ differs strongly from zero

189 and from the Gouy-Chapman model prediction and is sensitive to the stacking arrangement of the

190 clay layers ${ }^{38,92-94}$. Bourg et al. ${ }^{20}$ solved a two-dimensional form of the PBE near the edge

191 surface of an isolated montmorillonite layer (consistent with exfoliated layers in $\mathrm{Na}$ -

192 montmorillonite suspensions at ionic strengths lower than $I \sim 0.2$ ) and found that $\psi_{\text {edge }}$ was

193 reasonably described by:

$$
\frac{F \psi_{\text {edge }}}{R T}=A_{1} \operatorname{asinh}\left(A_{2}\left(Q_{\text {edge }}+A_{3}\right)\right)
$$

194 where $Q_{\text {edge }}\left(\mathrm{C} \cdot \mathrm{m}^{-2}\right)$ is the charge at the edge and $A_{1}$ (unitless), $A_{2}\left(\mathrm{~m}^{-2} \cdot \mathrm{C}\right)$ and $A_{3}\left(\mathrm{C} \cdot \mathrm{m}^{-2}\right)$ are

195 parameters that were fitted with the $\psi_{\text {edge }}$ values obtained from the full resolution of the 2D PB

196 equation. For montmorillonite at $25^{\circ} \mathrm{C}$, Tournassat et al. ${ }^{9}$ refined the values of these parameters

197 to: $A_{1}=1.4-1.2 \log I, A_{2}=11+\log I$, and $A_{3}=-0.02 \times(-\log I)^{1.60}$. This equation can be

198 compared with the classical Gouy-Chapman model for infinite planar surfaces ${ }^{13}$ :

$$
\frac{F \psi}{R T}=2 \operatorname{asinh}(B \cdot \sigma) \text { with } B=\frac{1}{\sqrt{8 \varepsilon \varepsilon_{0} R T \cdot 1000 \cdot I}}
$$


199 where $\sigma$ is the surface charge density (in $\mathrm{m}^{-2}$ ). A key prediction of Eq. 4 is that $\psi_{\text {edge }}$ is negative 200 when the edge surface charge is zero (Figure 2) because of a spillover of negative electrostatic 201 potential from the basal surfaces ${ }^{92,94}$.
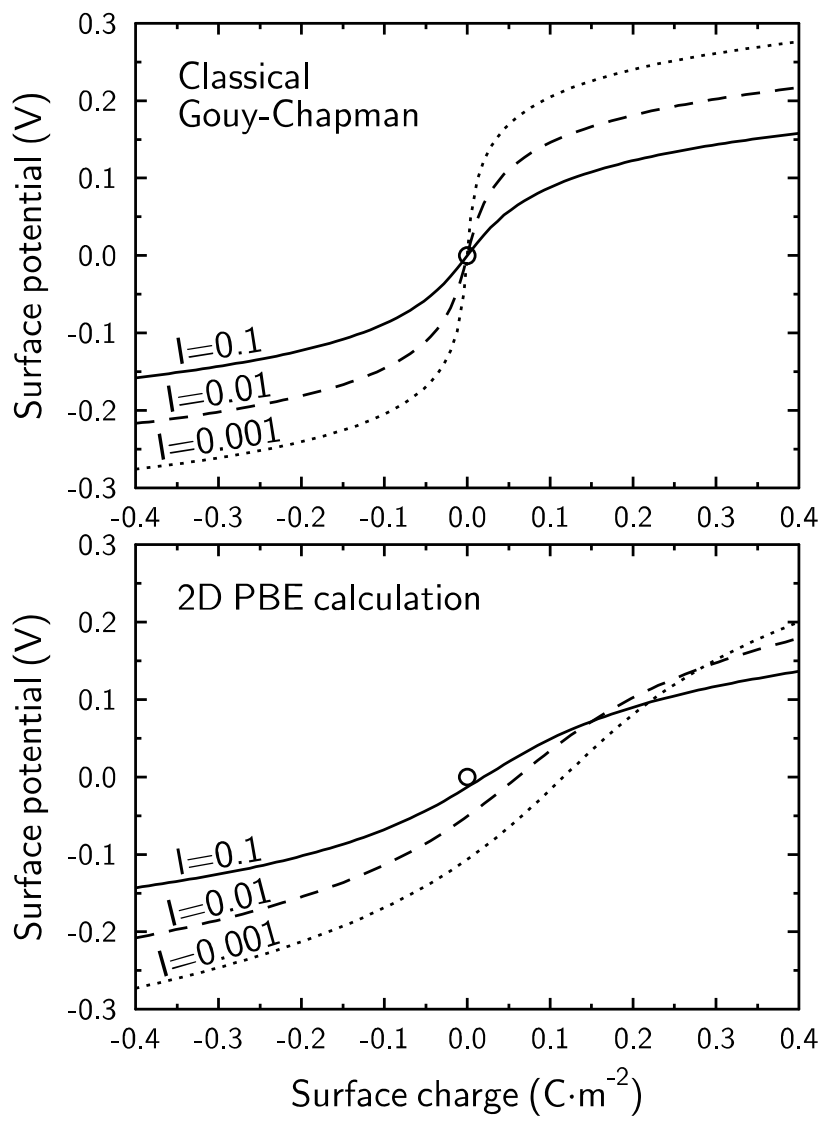

203 Figure 2. Comparison of the relationships between surface charge (horizontal axis) and surface

204 electrostatical potential (vertical axis) predicted by the classical Gouy-Chapman model for a flat

205 oxide surface (top) and by the PBE calculations of Bourg et al. ${ }^{20}$ for the edge surface of an 206 isolated montmorillonite layer (bottom) at three ionic strengths. The circles mark the condition of 207 zero charge and zero potential on each graph.

208 A potential limitation to the accuracy of the PBE is that it uses the mean-field theory 209 approximation, i.e., it neglects specific ion-ion and ion-surface site interactions. On infinite flat 
210 surfaces, the PBE is nevertheless known to adequately predict the structure of the electrical

211 double layer except at high salinities or in the presence of multivalent counterions ${ }^{37,95,96}$. In the

212 case of montmorillonite, an opportunity to verify the validity of Eq. (4) is provided by GCMC

213 simulations of the acid-base chemistry of individual clay particles where water was treated as a

214 uniform dielectric continuum ${ }^{50}$. To this end, we implemented Eq. (4) in PHREEQC ${ }^{97}$ (the

215 modification of the source code is made available in the supporting information file; a executable

216 file can be sent upon request) and predicted the protonation of surface sites using the same site

217 densities and $\mathrm{p} K_{\mathrm{a}}$ values as Delhorme et al. ${ }^{50}$ (PHREEQC scripts and database are available in

218 the supporting information file). An excellent agreement was found between the two predictions

219 (Figure 3), suggesting that Eq. (4) is valid over the entire range of experimental conditions where

220 montmorillonite particles are made of single layers. This condition is met in experiments carried

221 out with montmorillonite particles dispersed in a $\mathrm{NaCl}$ or $\mathrm{NaClO}_{4}$ background electrolyte at ionic

222 strengths lower than $I \sim 0.2^{98-101}$. 

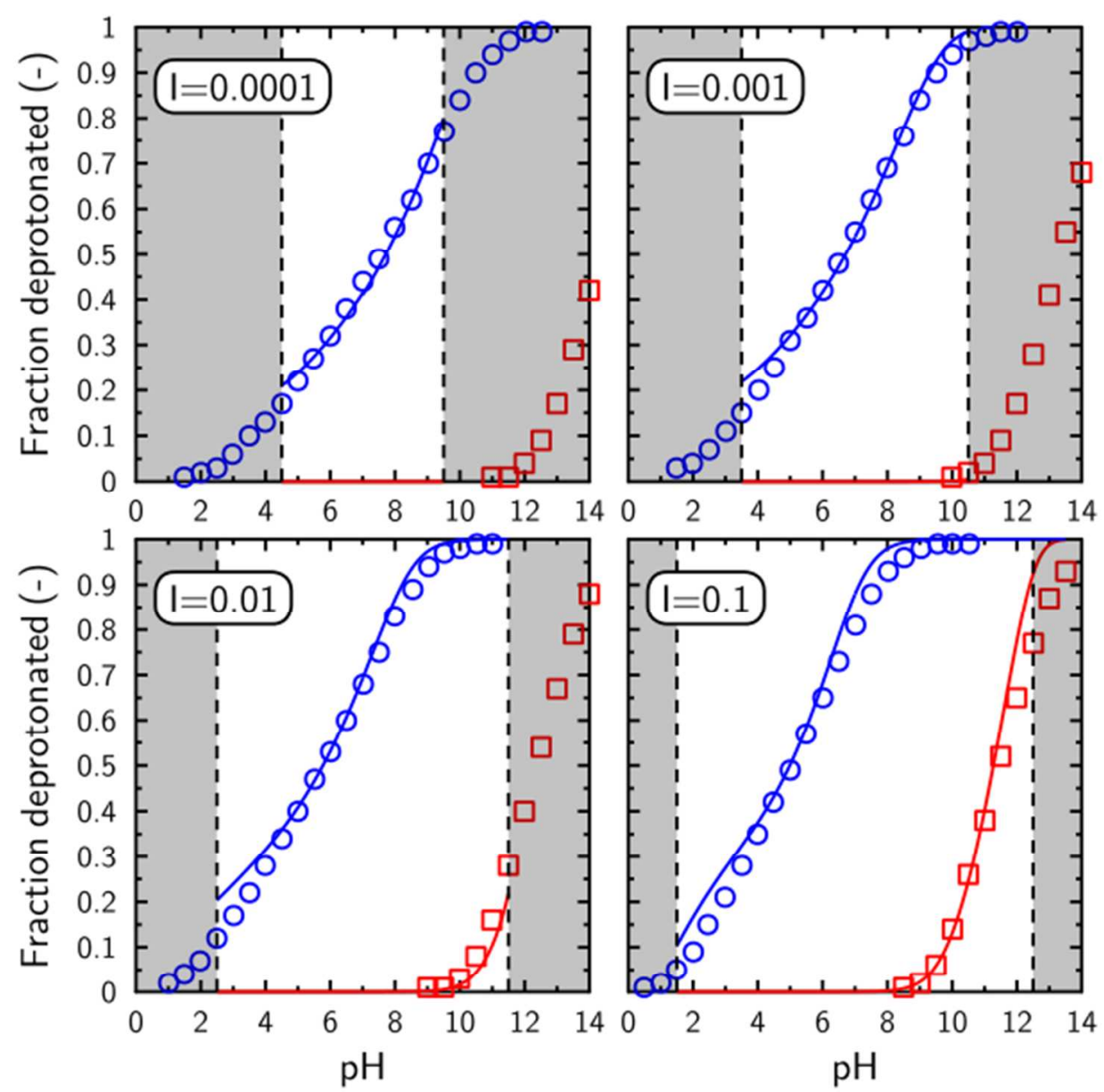

224 Figure 3. Comparison of the GCMC simulations of Delhorme et al. ${ }^{50}$ (circles and squares) with 225 an SCM that used Eq. (4) (solid lines) at three different ionic strengths in $\mathrm{NaCl}$ salt background.

226 Both models used the same site densities and intrinsic $\mathrm{p} K_{\mathrm{a}}$ values. Activity coefficients of solute 227 species in the SCM were modeled using the extended Debye-Hückel formalism. Blue symbols 228 and lines refer to aluminol sites having a $p K_{a}$ of 3.75 and a site density of $4.5 \mathrm{~nm}^{-2}$; red symbols 229 and lines refer to silanol sites having a $p K_{a}$ of 8.0 and a site density of $5.2 \mathrm{~nm}^{-2}$. Shaded areas 230 correspond to conditions that cannot exist, i.e., domains where the specified ionic strength is 231 exceeded because of high $\mathrm{H}^{+}$or $\mathrm{OH}^{-}$concentrations. 


\subsection{Intrinsic $p K_{a}$ values of edge surface sites}

233 Until recently, theoretical estimates of the intrinsic $\mathrm{p} K_{\mathrm{a}}$ values of edge surface sites were based on

234 bond-valence theories. The resulting predicted $\mathrm{p} K_{\mathrm{a}}$ values were highly sensitive to model

235 assumptions ${ }^{40,41}$ and did not provide accurate predictions of experimental montmorillonite

236 titration data ${ }^{20}$. In the last decade, $a b$ initio MD simulations have proved capable of accurately

237 predicting the intrinsic $\mathrm{p} K_{\mathrm{a}}$ values of simple oxide surface functional groups ${ }^{102-104}$, including

238 oxide-type functional groups on montmorillonite edge surfaces ${ }^{51-57}$. In particular, a series of

239 papers by Liu et al. ${ }^{51-55}$ explored the influence of edge crystallographic orientation and the

240 presence of octahedral and tetrahedral substitutions on the intrinsic $\mathrm{p} K_{\mathrm{a}}$ values of edge surface

241 groups. Their predictions are summarized in Figure 1. It is noteworthy that similar sites on the

242 surfaces perpendicular to the [010] and [110] crystallographic directions have different reactivity

243 according to the ab initio MD calculations. For example, silanol sites ( $>\mathrm{SiOH})$ have $\mathrm{p} K_{\mathrm{a}}$ values of

2447.0 on the [010] edge vs. 8.3 on the [110] edge when no octahedral substitution is present. These

245 values are significantly different from the values predicted by bond valence methods ${ }^{40,41}$ and

246 used by Bourg et al. ${ }^{20}$ (Table S-2).

\section{2.5. Experimental data}

248 Duc et al. ${ }^{26-28}$ carried out a comprehensive examination of montmorillonite acid-base titration

249 methodologies and identified a series of best practices. These included careful montmorillonite

250 pre-treatment and storage procedures (use of a series of acid washes at $\mathrm{pH} \approx 4$, exchangeable

251 cation homogenization at ionic strength $I \approx 1$, and rinsing steps; storage in liquid water at low

252 temperature for relatively short durations, or storage of freeze-dried samples as an acceptable

253 alternative). For the titration experiments themselves, they noted the importance of using an inert

254 atmosphere and limiting the experiments to the $\mathrm{pH}$ range $\approx 4.5-9.5$. They found that a continuous 
255 titration method was acceptable if equilibration times between additions of acid or base were

256 short (<10 $\mathrm{min})$ and if hysteresis was quantified; alternatively, a discontinuous batch titration 257 method was acceptable if the atoms released by clay dissolution ( $\mathrm{Si}, \mathrm{Al}, \mathrm{Mg}, \mathrm{Fe}$ ) were analyzed 258 (both in solution and on the clay cation-exchange sites) to account for $\mathrm{pH}$ buffering by side 259 reactions. In the alkaline domain, however, correction of the raw batch titration data for measured 260 side reactions failed to reproduce the continuous titration curves. The authors concluded on the 261 superiority of fast, continuous methods for quantifying the dissociable surface charge of clays.

262 Among the many reported studies of montmorillonite titration ${ }^{12,27-29,33-35,39,80,84,86,88-90,105}$, Bourg

263 et al. ${ }^{20}$ determined that only three studies ${ }^{27,28,39}$ followed this set of best practices. One of these 264 studies used the batch titration technique ${ }^{39}$, and its results at alkaline $\mathrm{pH}$ values are therefore of 265 unclear reliability. Of the acid-base titration studies published over the last decade ${ }^{42-47}$, none 266 followed the entire established set of best practices while also reporting the $\mathrm{pH}$ and ionic strength 267 of the solutions used during clay pre-treatment. The present study, therefore, focuses on the 268 dataset from Duc et al. ${ }^{27}$ as the best available set of montmorillonite acid-base titration results.

269 An interesting indirect quantification of edge surface charge was pursued by Pecini and Avena ${ }^{48}$, 270 who measured the i.e.p. of montmorillonite loaded with cationic dyes with a strong affinity for

271 the basal surface. Under the assumption that the dyes completely screen the basal surface charge 272 but do not interact with the edge surfaces (such that the measured i.e.p. reflects edge surface 273 properties) and within the well-established theoretical limitations associated with relating an i.e.p. 274 to a point of zero charge ${ }^{30}$, the results of Pecini and Avena ${ }^{48}$ suggest that the point of zero 275 charge of clay edge surfaces (the $\mathrm{pH}$ value where $\sigma_{0 \text {,edge }}+\sigma_{\mathrm{H}}=0$, where $\sigma_{0, \text { edge }}$ corresponds to the 276 permanent structural charge density "expressed" on the edge surface) is in the $\mathrm{pH}$ range 3.8-5.5, 277 in qualitative agreement with a previous measurement of the i.e.p. of thermally treated $\mathrm{Cu}-$ 
278 montmorillonite for which the structural layer charge was reduced to almost zero, whereby the 279 authors estimated that the edge surfaces are negatively charged at $\mathrm{pH}>3.5^{106}$.

\section{3. Towards a predictive SCM for montmorillonite edge surfaces}

\section{$281 \quad 3.1$. Reactivity of edge surface functional groups}

282 To determine whether the new knowledge summarized above allows a predictive simulation of 283 the acid-base chemistry of montmorillonite, we developed a generic SCM for the [010] and [110] 284 edge surfaces in our modified version of PHREEQC that applies Eq. (4) for the calculation of $285 \psi_{\text {edge. }}$ Edge surface functional groups were modeled as groups of one octahedral and two 286 tetrahedral cations together with their associated $\mathrm{OH}$ groups. The overall charge of a group was 287 calculated from bond valence principle applied to the terminal oxygen atoms of the edge sites. 288 For example, a fully-deprotonated functional group with no isomorphic substitution on the [010] 289 edge corresponds to the grouping of two $\mathrm{Si}^{-} \mathrm{O}^{-}$sites and one $\mathrm{Al}-(\mathrm{OH})_{2}^{-}$site and is denoted $>\mathrm{Si}-\mathrm{Al}-$ $290 \mathrm{SiO}_{4}^{-3}$ (leaving the unreactive $\mathrm{H}$ out of the formula). It can be protonated four times with intrinsic $291 \mathrm{p} K_{\mathrm{a}}$ values of $8.3,7,7$, and 3.1 as predicted by ab initio MD simulation (section 2.4 and Figure

292 1). This representation deviates from the classical description used in SCMs, where each surface 293 hydroxyl is modeled as a distinct functional group with a single $\mathrm{p} K_{\mathrm{a}}$ value ${ }^{107}$. The advantages of

294 the present representation are that the calculation of the number of sites affected by neighboring 295 substitutions is straightforward and that future implementation of metal adsorption through the 296 formation of multi-dentate surface complexes is made easier with regards to the calculation of 297 surface site activities ${ }^{9,108}$. Simple cases were used to verify that the grouping of surface sites had 298 little effect on model predictions (Fig. SI-1 in supporting information; PHREEQC script files are 299 also available in order to test further the effect of grouping sites). The fractions of edge functional 
300 groups that include octahedral or tetrahedral substitutions were calculated from the structural

301 formula of montmorillonite with the assumption that edge chemistry reflects that of the bulk

302 mineral. Because of the absence of ab initio MD simulation predictions of the reactivity of Fe-

303 substituted sites on the [110] edge surface, sites with Fe(III) for Al substitutions on this surface

304 were assigned the same properties as sites without substitutions, while sites with Fe(II) for Al

305 substitutions were assigned the same properties as sites with $\mathrm{Mg}$ for Al substitutions. Surface site

306 densities were estimated from crystallographic considerations and from reported clay unit cell

307 formulae: each site group, SiAlSi, AlAlSi, SiMgSi, SiFe ${ }^{\mathrm{III}} \mathrm{Si}$, and $\mathrm{SiFe}{ }^{\mathrm{II}} \mathrm{Si}$ had a density of $2.06 \times$

$308 x_{i} \quad \mathrm{~nm}^{-2}, \quad$ where $\quad x_{>\mathrm{Si}-\mathrm{Mg}-\mathrm{Si}}=\left(\frac{\mathrm{Mg}}{\mathrm{Al}+\mathrm{Mg}+\mathrm{Fe}^{\mathrm{II}}+\mathrm{Fe}^{\mathrm{III}}}\right)_{\text {oct }}, \quad x_{>\mathrm{Si}-\mathrm{Fe}^{\mathrm{III}}-\mathrm{Si}}=\left(\frac{\mathrm{Fe}^{\mathrm{III}}}{\mathrm{Al}+\mathrm{Mg}^{\mathrm{II}}+\mathrm{Fe}^{\mathrm{II}}+\mathrm{Fe}^{\mathrm{III}}}\right)_{\text {oct }}$

$309, x_{>\mathrm{Si}-\mathrm{Fe}^{\mathrm{II}}-\mathrm{Si}}=\left(\frac{\mathrm{Fe}^{\mathrm{II}}}{\mathrm{Al}+\mathrm{Mg}+\mathrm{Fe}^{\mathrm{II}}+\mathrm{Fe}^{\mathrm{III}}}\right)_{\text {oct }} \quad, \quad x_{>\mathrm{Al}-\mathrm{Al}-\mathrm{Si}}=2 \times\left(\frac{\mathrm{Al}}{\mathrm{Si}+\mathrm{Al}}\right)_{\text {tet }}, \quad$ and $\quad x_{>\mathrm{Si}-\mathrm{Al}-\mathrm{Si}}=1-$

$310 x_{>\mathrm{Si}-\mathrm{Mg}-\mathrm{Si}}-x_{>\mathrm{Al}-\mathrm{Al}-\mathrm{Si}}-x_{>\mathrm{Si}-\mathrm{Fe}^{\mathrm{III}}-\mathrm{Si}}-x_{>\mathrm{Si}-\mathrm{Fe}^{\mathrm{II}}-\mathrm{Si}}$. This calculation implicitly neglects the

311 possible existence of edge sites with both octahedral and tetrahedral substitutions or with two

312 tetrahedral substitutions, for which predicted $\mathrm{p} K_{\mathrm{a}}$ values are not available.

\section{3.2. Impact of clay permanent structural charge}

314 Proton adsorption by Na-H cation exchange on basal surfaces was taken into account by using a

315 constant selectivity coefficient of $3.2(\log K=0.5)$ in near agreement with previously published

316 values ${ }^{41,109}$. The permanent structural charge was set to $0.9 \mathrm{~mol}_{\mathrm{c}} \cdot \mathrm{kg}^{-1}$, yielding an overall charge

317 density of $\sigma_{0}=-0.12 \mathrm{C} \cdot \mathrm{m}^{-2}$ for the clay layers. As noted above, the edge surface charge equals

$318 \sigma_{0, \text { edge }}+\sigma_{\mathrm{H}}=0$, where $\sigma_{0, \text { edge }}$ is the edge surface charge density resulting from nearby isomorphic

319 substitutions. Bourg et al. ${ }^{20}$ assumed that $\sigma_{0 \text {,edge }}=\sigma_{0}$ for simplicity. Here, we modeled edge

320 surface charge arising from near-edge isomorphic substitutions in an even simpler way: we added

$321-1$ to the valence of edge functional groups that include an isomorphic substitution of Al for $\mathrm{Si}$ or 
322 of $\mathrm{Mg}$ or $\mathrm{Fe}(\mathrm{II})$ for $\mathrm{Al}$. For example, a fully-deprotonated edge functional group with no

323 isomorphic substitutions $\left(>\mathrm{Si}-\mathrm{Al}_{-}-\mathrm{SiO}_{4}{ }^{-3}\right)$, upon substitution of $\mathrm{Mg}$ for $\mathrm{Al}$, becomes $\left(>\mathrm{Si}-\mathrm{Mg}_{-}-\mathrm{SiO}_{4}{ }^{-}\right.$ $\left.3244^{4}\right)$.

\section{3.3. Predicted acid-base properties of edge surfaces}

326 According to the predictive model described above, montmorillonite edge surface charge has

327 little dependence on the type and extent of layer structural substitutions, but it depends

328 significantly on crystallographic orientation between the [010] and [110] edge surfaces (Figure 4,

329 top). In the presence of $0.1 \mathrm{~mol} \cdot \mathrm{L}^{-1} \mathrm{NaCl}$, the [010] surface is positively charged at $\mathrm{pH}<5$,

330 whereas the [110] surface is positively charged only at $\mathrm{pH}<3.5$, consistent with the experimental

331 findings of Thomas et al. ${ }^{106}$ and Pecini and Avena ${ }^{48}$. The relative proportion of [010] and [110]

332 edge surface orientations on montmorillonite is unfortunately unknown, which leaves one

333 unavoidable free parameter in the presently developed SCM.

334 Changes in ionic strength are predicted to have a marked effect on surface charge but not on the

335 shape of the charge vs. $\mathrm{pH}$ curves, especially for the surface perpendicular to [110] (Figure 4,

336 bottom). A decrease in ionic strength results primarily in a translation of the surface charge curve

337 towards higher $\mathrm{pH}$ values, in agreement with experimental results. 

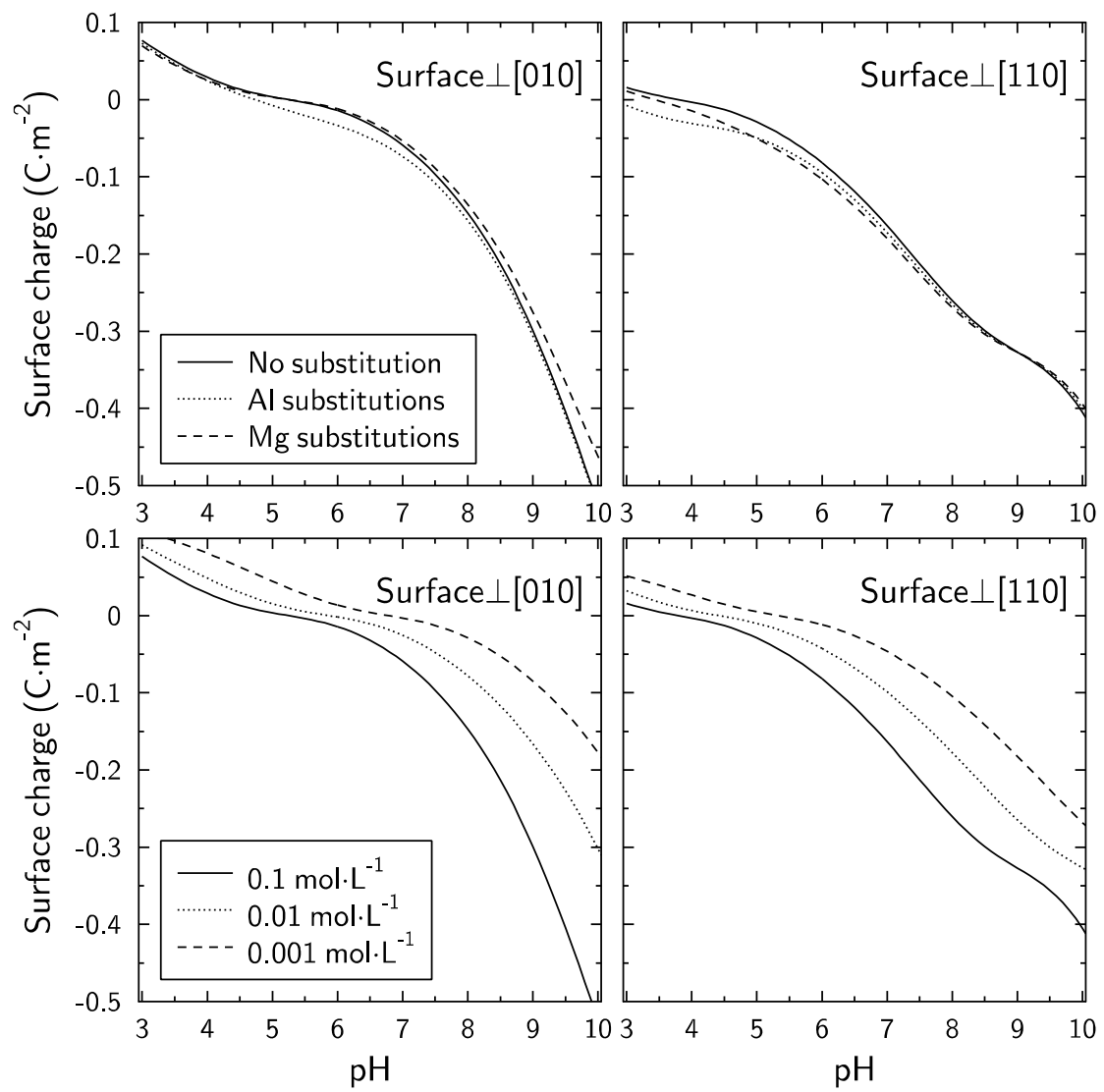

339 Figure 4. Top: Predicted edge surface charge as a function of $\mathrm{pH}$ for montmorillonite particles

340 immersed in a $0.1 \mathrm{~mol} \cdot \mathrm{L}^{-1} \mathrm{NaCl}$ background electrolyte. "No", "Al" and "Mg" substitutions refer

341 to simulations carried out with $\left(x_{>\mathrm{Si}-\mathrm{Mg}-\mathrm{Si}}=0 ; x_{>\mathrm{Al}-\mathrm{Al}-\mathrm{Si}}=0\right),\left(x_{>\mathrm{Si}-\mathrm{Mg}-\mathrm{Si}}=0 ; x_{>\mathrm{Al}-\mathrm{Al}-\mathrm{Si}}=\right.$

$3420.1)$ and $\left(x_{>\mathrm{Si}-\mathrm{Mg}-\mathrm{Si}}=0.2 ; x_{>\mathrm{Al}-\mathrm{Al}-\mathrm{Si}}=0\right)$ respectively. Bottom: Influence of $\mathrm{NaCl}$

343 concentration $\left(0.001,0.01\right.$, and $\left.0.1 \mathrm{~mol} \cdot \mathrm{L}^{-1}\right)$ on the predictions obtained if $x>\mathrm{Si}-\mathrm{Al}-\mathrm{Si}=1$.

\section{3.4. Comparison with potentiometric titration data}

345 Model predictions were compared with the potentiometric titration results of Duc et al. ${ }^{27}$ for the

346 SWy-2 and MX80 reference montmorillonites (the dataset for SWy-2 was made available in

347 Delhorme et al. ${ }^{50}$ ). The structural formulae of SWy-2 and MX80 montmorillonites were reported 
$349\left(\mathrm{Si}_{4}\right)\left(\mathrm{Al}_{1.57} \mathrm{Mg}_{0.25} \mathrm{Fe}^{\mathrm{III}}{ }_{0.09} \mathrm{Fe}^{\mathrm{II}}{ }_{0.09}\right) \mathrm{Na}_{0.34} \mathrm{O}_{10}(\mathrm{OH})_{2}$, respectively ${ }^{27}$. Reported montmorillonite 350 structural formulae can vary as a function of sample preparation and calculation method ${ }^{65}$. This 351 variability adds a minor source of uncertainty to our model predictions according to Figure 4 . The $352 x_{>\mathrm{Si}-\mathrm{Mg}-\mathrm{Si}}, x_{>\mathrm{Si}-\mathrm{Fe}^{\mathrm{II}}-\mathrm{Si}}, x_{>\mathrm{Si}-\mathrm{Fe}^{\mathrm{III}}-\mathrm{Si}}$ and $x_{>\mathrm{Al}-\mathrm{Al}-\mathrm{Si}}$ values were set, respectively, to 0.125 , $3530.045,0.045$ and 0 for MX80 montmorillonite and to $0.125,0.003,0.112$ and 0.13 for SWy-2 354 montmorillonite.

355 A good agreement was found between experimental and predicted potentiometric titration data 356 for SWy-2 montmorillonite if the specific edge surface area was set to $14 \mathrm{~m}^{2} \cdot \mathrm{g}^{-1}$ and the relative 357 abundance of [010] and [110] edges was set to 1:1 (Figure 5). The modeled edge specific surface 358 area is in agreement with the value of $19.2 \mathrm{~m}^{2} \cdot \mathrm{g}^{-1}$ measured on the sample used for the titration 359 experiment (Table S-1), because the DIS method tends to overestimate the surface area ${ }^{74}$. A 360 lesser agreement was found for the lowest ionic strength $(I=0.001)$ at $\mathrm{pH}$ values greater than 8 , 361 but the significance of this discrepancy is tempered by the increased experimental uncertainty at $362 \mathrm{pH}>9^{20}$. For MX80 montmorillonite, the agreement between experimental and predicted 363 potentiometric titration curves was acceptable if the specific edge surface area was set to $12 \mathrm{~m}^{2} \cdot \mathrm{g}^{-}$

$364^{1}$ and the relative abundance of [010] and [110] edges was set to $1: 1$ (Figure 5) (the effect of 365 varying the relative abundance of [010] and [110] edges can be seen on Figure 4, and it can be 366 quantified by using the PHREEQC script files provided in the supporting information). The 367 modeled edge specific surface area was larger than the measured value (Table S-1, from 6 to 9 $368 \mathrm{~m}^{2} \cdot \mathrm{g}^{-1}$, depending on the considered study). However, the values reported in Table S-1 were not 369 measured for the same samples used in the titration experiments. For both titration datasets, the $370 \mathrm{pH}$ values corresponding to $\delta \sigma_{\mathrm{H}}=0$ were correctly predicted at all investigated ionic strengths.

371 A better agreement with the experimental data likely could have been achieved by adjusting the 
$372 \mathrm{p} K_{\mathrm{a}}$ values of edge surface sites in the limit of the uncertainty reported in Liu et al. ${ }^{51-55}$ (from

$373 \pm 0.6$ to \pm 1.6 depending on the site under consideration), but such a refinement was not deemed

374 justified in light of the uncertainties in the experimental data. Such exercise can be done using the

375 files made available in the supporting information.
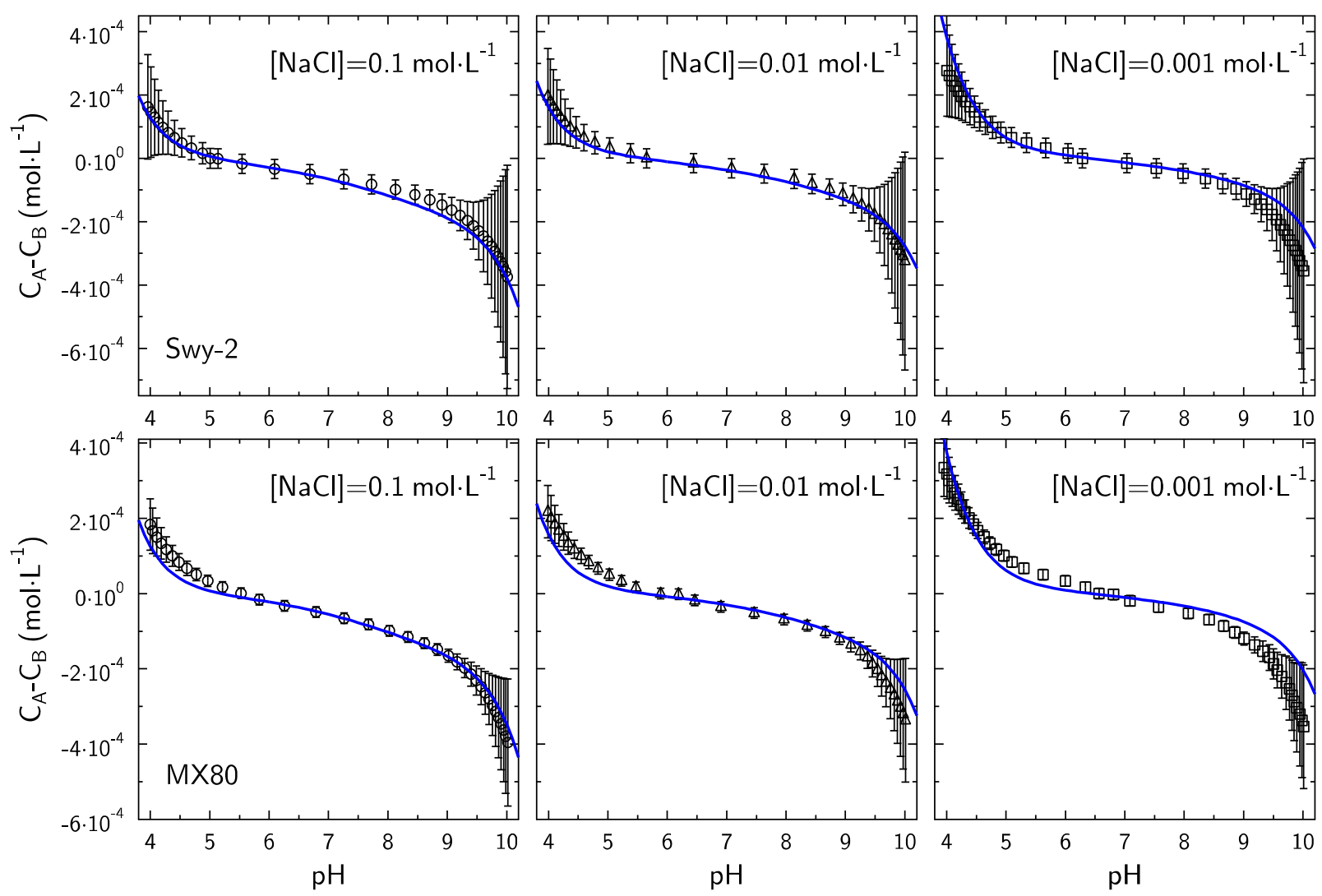

376

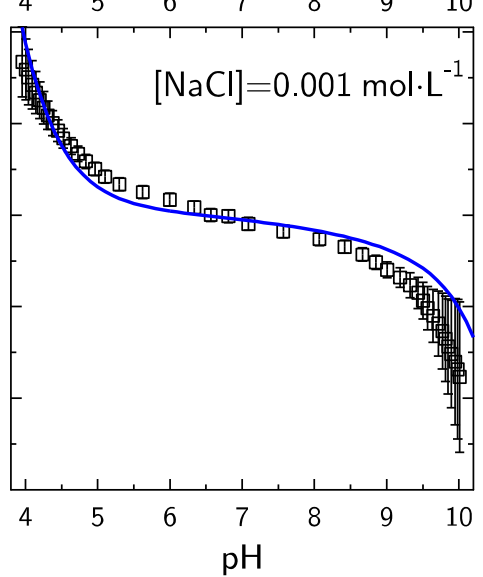

377 Figure 5. Comparison of model predictions (lines) and potentiometric titration data (symbols ${ }^{27,50}$ )

378 for MX80 montmorillonite (bottom) and SWy-2 montmorillonite (top). The specific edge surface

379 area was set to $12 \mathrm{~m}^{2} \cdot \mathrm{g}^{-1}$ and $14 \mathrm{~m}^{2} \cdot \mathrm{g}^{-1}$ for MX80 and Swy-2 montmorillonite respectively, and

380 the relative abundance of [010] and [110] edges was set at 0.5/0.5. Error bands were estimated as

381 in Bourg et al. ${ }^{20}$. 
382 The present study relies on several simplifying assumptions or conditions that inherently limit the

383 range of applicability of the proposed model. First and foremost, the model was derived for the

384 case of simple indifferent $1: 1$ electrolytes such as $\mathrm{NaCl}$ at relatively dilute concentrations $(\leq 0.1$

385 M) where clay layer stacking is minimal and where the mean field approximation inherent in the

386 PBE is valid. Extension of the model to a broader set of conditions would require a new model of

$387 \psi_{\text {edge }}$ derived for the appropriate aggregation structure of montmorillonite layers and for

388 deviations from the mean-field approximation. A significant challenge to such an extension is

389 that the best-quality experimental titration data are limited to the conditions modeled in the 390 present study.

391 Another important condition for the applicability of our proposed model is that the model's

392 description of edge surface sites must be accurate. At the most fundamental level, this condition

393 can be challenged on the grounds that most, if not all, theoretical calculations of montmorillonite

394 edge site properties were carried out based on a pyrophillite-like model structure, which is trans-

395 vacant, whereas available data suggest that most montmorillonites have a cis-vacant structure

396 110,111. Structural OH groups have different positions in cis- and trans-vacant structures.

397 Additionally, cis-vacant structures are not centrosymmetric ${ }^{111}$, and the types of edge surface

398 configurations are thus more diverse than for trans-vacant structures. In particular, edge surface

399 site configurations are different for the edges perpendicular to the [010] and [010]

400 crystallographic directions in a cis-vacant structure, whereas they are the same in a trans-vacant

401 structure (see Figure S-1 in supporting information). 


\section{Acknowledgement}

403

404

405

406

407

408

409

410

411
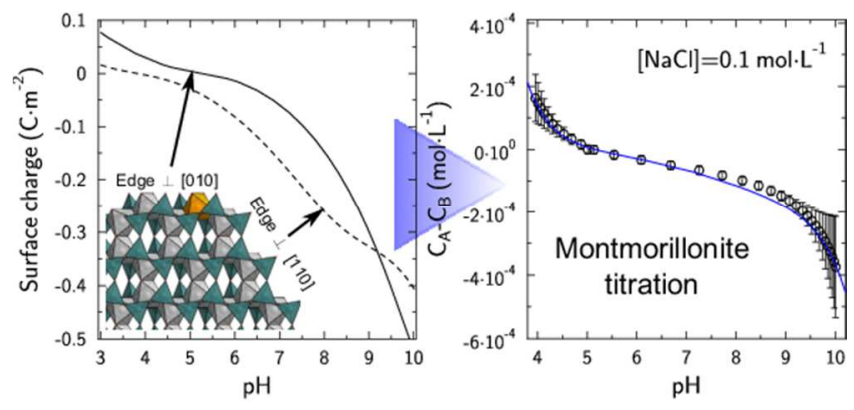
Sciences, Geosciences program.

\section{TOC}

This work was supported by the French Radioactive Waste Management Agency (Andra) in the framework of the Andra-BRGM scientific partnership (CTEC project). J.A.D. acknowledges funding from L'Institut Carnot for his visit to the BRGM and from the U.S. Department of Energy under Contract DE-AC02-05CH11231 under the auspices of the Office of Nuclear Energy, Used Fuel Disposition program. I.C.B. was supported by the U.S. Department of Energy under Contract DE-AC02-05CH11231 through the Office of Science, Office of Basic Energy

\section{References}

(1) Bourg, I. C. Sealing shales versus brittle shales: A sharp threshold in the material properties and energy technology uses of fine-grained sedimentary rocks. Env. Sci. Tech.

(2) Tournassat, C.; Bourg, I. C.; Steefel, C. I.; Bergaya, F. Introduction; In Natural and Engineered Clay Barriers; Tournassat, C.; Steefel, C. I.; Bourg, I. C.; Bergaya, F., Eds.;

(3) Borisover, M.; Davis, J. A. Chapter 2 - Adsorption of inorganic and organic solutes by clay minerals; In Natural and Engineered Clay Barriers; Tournassat, C.; Steefel, C. I.; Bourg, I. C.; Bergaya, F., Eds.; Developments in Clay Science; Elsevier, 2015; Vol. 6, pp. 33-70. 
424

425

426

427

428

429

430

431

432

433

434

435

436

437

438

439

440

441

442

443

444

445

446

447

448

449

450

451

452

453

454

455

456

457

458

459

460

461

462

463

464

465

466

467

468

469

(4) Bourg, I. C.; Tournassat, C. Chapter 6 - Self-diffusion of water and ions in clay barriers; In Natural and Engineered Clay Barriers; Tournassat, C.; Steefel, C. I.; Bourg, I. C.; Bergaya, F., Eds.; Developments in Clay Science; Elsevier, 2015; Vol. 6, pp. 71-100.

(5) Bourg, I. C.; Sposito, G. Ion exchange phenomena; In Handbook of Soil Science, second edition; Huang, P. M.; Li, Y.; Sumner, M. E., Eds.; CRC Press: Boca Raton, 2011.

(6) Manning, B. A.; Goldberg, S. Adsorption and stability of arsenic(III) at the clay mineralwater interface. Env. Sci. Tech. 1997, 31, 2005-2011.

(7) Schlegel, M. L.; Manceau, A. Evidence for the nucleation and epitaxial growth of $\mathrm{Zn}$ phyllosilicate on montmorillonite. Geochim. Cosmochim. Acta 2006, 70, 901-917.

(8) Strawn, D. G.; Sparks, D. L. The use of XAFS to distinguish between inner-and outersphere lead adsorption complexes on montmorillonite. J. Colloid Interface Sci. 1999, 216, 257-269.

(9) Tournassat, C.; Grangeon, S.; Leroy, P.; Giffaut, E. Modeling specific pH dependent sorption of divalent metals on montmorillonite surfaces. A review of pitfalls, recent achievements and current challenges. Am. J. Sci. 2013, 313, 395-451.

(10) Marty, N. C. M.; Cama, J.; Sato, T.; Chino, D.; Villiéras, F.; Razafitianamaharavo, A.; Brendlé, J.; Giffaut, E.; Soler, J. M.; Gaucher, E. C.; Tournassat, C. Dissolution kinetics of synthetic Na-smectite. An integrated experimental approach. Geochim. Cosmochim. Acta 2011, 75, 5849-5864.

(11) Yang, L.; Steefel, C. I. Kaolinite dissolution and precipitation kinetics at $22{ }^{\circ} \mathrm{C}$ and $\mathrm{pH} 4$. Geochim. Cosmochim. Acta 2008, 72, 99-116.

(12) Tombácz, E.; Szekeres, M. Surface charge heterogeneity of kaolinite in aqueous suspension in comparison with montmorillonite. Appl. Clay Sci. 2006, 34, 105-124.

(13) Davis, J. A.; James, R. O.; Leckie, J. O. Surface ionization and complexation at the oxide/water interface: I. Computation of electrical double layer properties in simple electrolytes. J. Colloid Interface Sci. 1978, 63, 480-499.

(14) Solomon, T. The definition and unit of ionic strength. J. Chem. Educ. 2001, 78, 16911692.

(15) Bickmore, B. R.; Tadanier, C. J.; Rosso, K. M. New approach for predicting acidity constants: Combining bond-valence and ab initio methods. Abstracts of Papers of the American Chemical Society 2004, 227, U1203-U1203.

(16) Goldberg, S.; Criscenti, L. J. Modeling adsorption of metals and metalloids by soil components; In Biophysico-chemical processes of heavy metals and metalloids in soil environments; Violante, A.; Huang, P. M.; Gadd, G. M., Eds.; John Wiley \& Sons, Hoboken, N J, 2008; pp. 215-264.

(17) Machesky, M. L.; Predota, M.; Wesolowski, D. J.; Vlcek, L.; Cummings, P. T.; Rosenqvist, J.; Ridley, M. K.; Kubicki, J. D.; Bandura, A. V.; Kumar, N.; Sofo, J. O. Surface protonation at the rutile (110) interface: explicit incorporation of solvation structure within the refined MUSIC model framework. Langmuir 2008, 24, 1233112339.

(18) Sposito, G. Characterization of particle surface charge; In Environmental particles; Buffle, J.; Van Leeuwen, H. P., Eds.; Lewis Publisher, Chelsea, Michigan, USA, 1992; Vol. 1, pp. 291-314.

(19) Sverjensky, D. A.; Sahai, N. Theoretical prediction of single-site surface-protonation equilibrium constants for oxides and silicates in water. Geochim. Cosmochim. Acta 1996, $60,3773-3797$. 
470

471

472

473

474

475

476

477

478

479

480

481

482

483

484

485

486

487

488

489

490

491

492

493

494

495

496

497

498

499

500

501

502

503

504

505

506

507

508

509

510

511

512

513

514

515

516

(20) Bourg, I. C.; Sposito, G.; Bourg, A. C. M. Modeling the acid-base surface chemistry of montmorillonite. J. Colloid Interface Sci. 2007, 312, 297-310.

(21) Bargar, J. R.; Fuller, C. C.; Marcus, M. A.; Brearley, A. J.; Rosa, M. P. De la; Webb, S. M.; Caldwell, W. A. Structural characterization of terrestrial microbial Mn oxides from Pinal Creek, AZ. Geochim. Cosmochim. Acta 2009, 73, 889-910.

(22) Manceau, A.; Kersten, M.; Marcus, M. A.; Geoffroy, N.; Granina, L. Ba and Ni speciation in a nodule of binary Mn oxide phase composition from Lake Baikal. Geochim. Cosmochim. Acta 2007, 71, 1967-1981.

(23) Trolard, F.; Bourrié, G.; Abdelmoula, M.; Refait, P.; Feder, F. Fougerite, a new mineral of the pyroaurite-iowaite group: description and crystal structure. Clays Clay Miner. 2007, 55, 323-334.

(24) Wang, S.-L.; Liu, C. H.; Wang, M. K.; Chuang, Y. H.; Chiang, P. N. Arsenate adsorption by $\mathrm{Mg} / \mathrm{Al}-\mathrm{NO} 3$ layered double hydroxides with varying the $\mathrm{Mg} / \mathrm{Al}$ ratio. Appl. Clay Sci. 2009, 43, 79-85.

(25) Duc, M.; Carteret, C.; Thomas, F.; Gaboriaud, F. Temperature effect on the acid-base behaviour of Na-montmorillonite. J. Colloid Interface Sci. 2008, 327, 472-476.

(26) Duc, M.; Gaboriaud, F.; Thomas, F. Sensitivity of the acid-base properties of clays to the methods of preparation and measurement: 1. Literature review. J. Colloid Interface Sci. 2005, 289, 139-147.

(27) Duc, M.; Gaboriaud, F.; Thomas, F. Sensitivity of the acid-base properties of clays to the methods of preparation and measurement: 2. Evidence from continuous potentiometric titrations. J. Colloid Interface Sci. 2005, 289, 148-156.

(28) Duc, M.; Thomas, F.; Gaboriaud, F. Coupled chemical processes at clay/electrolyte interface: A batch titration study of Na-montmorillonites. J. Colloid Interface Sci. 2006, 300, 616-625.

(29) Tournassat, C.; Greneche, J.-M.; Tisserand, D.; Charlet, L. The titration of clay minerals. Part I. Discontinuous backtitration technique combined to CEC measurements. J. Colloid Interface Sci. 2004, 273, 224-233.

(30) Sposito, G. On points of zero charge. Environ. Sci. Technol. 1998, 32, 2815-2819.

(31) Davis, J. A.; Kent, D. Surface complexation modeling in aqueous geochemistry. Rev. Mineral. Geochem. 1990, 23, 177-260.

(32) Sondi, I.; Biscan, J.; Pravdic, V. Electrokinetics of pure clay minerals revisited. $J$. Colloid Interface Sci. 1996, 178, 514-522.

(33) Tertre, E.; Castet, S.; Berger, G.; Loubet, M.; Giffaut, E. Surface chemistry of kaolinite and Na-montmorillonite in aqueous electrolyte solutions at 25 and 60egreC: Experimental and modeling study. Geochim. Cosmochim. Acta 2006, 70, 4579-4599.

(34) Tombácz, E.; Szekeres, M. Colloidal behavior of aqueous montmorillonite suspensions: the specific role of $\mathrm{pH}$ in the presence of indifferent electrolytes. Appl. Clay Sci. 2004, 27, 75-94.

(35) Avena, M. J.; De Pauli, C. Proton adsorption and electrokinetics of an argentinean montmorillonite. J. Colloid Interface Sci. 1998, 202, 195-204.

(36) Żalac, S.; Kallay, N. Application of mass titration to the point of zero charge determination. J. Colloid Interface Sci. 1992, 149, 233-240.

(37) Sposito, G. The surface chemistry of natural particles; Oxford University Press: New York, 2004; p. 242.

(38) Kraepiel, A. M. L.; Keller, K.; Morel, F. M. M. On the acid-base chemistry of permanently charged minerals. Env. Sci. Tech. 1998, 32, 2829-2838. 
517

518

519

520

521

522

523

524

525

526

527

528

529

530

531

532

533

534

535

536

537

538

539

540

541

542

543

544

545

546

547

548

549

550

551

552

553

554

555

556

557

558

559

560

561

562

(39) Baeyens, B.; Bradbury, M. H. A mechanistic description of Ni and Zn sorption on Namontmorillonite. Part I: Titration and sorption measurements. J. Contam. Hydrol. 1997, 27, 199-222.

(40) Bickmore, B. R.; Rosso, K. M.; Nagy, K. L.; Cygan, R. T.; Tadanier, C. J. Ab initio determination of edge surface structures for dioctahedral 2:1 phyllosilicates: Implications for acid-base reactivity. Clays Clay Miner. 2003, 51, 359-371.

(41) Tournassat, C.; Ferrage, E.; Poinsignon, C.; Charlet, L. The titration of clay minerals II. Structure-based model and implications for clay reactivity. J. Colloid Interface Sci. 2004, 273, 234-246.

(42) Bogolepov, A. A. Simulation of U(VI) and $\mathrm{Co}(\mathrm{II})$ sorption on montmorillonite. Radiochemistry (Moscow, Russian Federation)(Translation of Radiokhimiya) 2009, 51, 96-103.

(43) Gu, X. Y.; Evans, L. J.; Barabash, S. J. Modeling the adsorption of $\mathrm{Cd}(\mathrm{II}), \mathrm{Cu}(\mathrm{II}), \mathrm{Ni}(\mathrm{II})$, $\mathrm{Pb}(\mathrm{II})$ and $\mathrm{Zn}$ (II) onto montmorillonite. Geochim. Cosmochim. Acta 2010, 74, 57185728.

(44) Korichi, S.; Bensmaili, A. Sorption of uranium (VI) on homoionic sodium smectite experimental study and surface complexation modeling. J. Hazard. Mater. 2009, 169, 780-793.

(45) Kriaa, A.; Hamdi, N.; Srasra, E. Acid-base chemistry of montmorillonitic and beidelliticmontmorillonitic smectite. Russ. J. Electrochem. 2007, 43, 167-177.

(46) Rozalén, M.; Brady, P. V.; Huertas, F. J. Surface chemistry of K-montmorillonite: Ionic strength, temperature dependence and dissolution kinetics. J. Colloid Interface Sci. 2009, $333,474-484$.

(47) Tan, X. L.; Hu, J.; Zhou, X.; Yu, S. M.; Wang, X. K. Characterization of Lin'an montmorillonite and its application in the removal of $\mathrm{Ni2}+$ from aqueous solutions. Radiochim. Acta 2008, 96, 487-495.

(48) Pecini, E. M.; Avena, M. J. Measuring the isoelectric point of the edges of clay mineral particles: The case of montmorillonite. Langmuir 2013, 29, 14926-14934.

(49) Le Forestier, L.; Muller, F.; Villiéras, F.; Pelletier, M. Textural and hydration properties of a synthetic montmorillonite compared with a natural Na-exchanged clay analogue. Appl. Clay Sci. 2010, 48, 18-25.

(50) Delhorme, M.; Labbez, C.; Caillet, C.; Thomas, F. Acid-base properties of 2:1 clays. I. Modeling the role of electrostatics. Langmuir 2010, 26, 9240-9249.

(51) Liu, X.; Cheng, J.; Sprik, M.; Lu, X.; Wang, R. Interfacial structures and acidity of edge surfaces of ferruginous smectites. Geochim. Cosmochim. Acta 2015, 168, 293-301.

(52) Liu, X.; Cheng, J.; Sprik, M.; Lu, X.; Wang, R. Surface acidity of 2:1-type dioctahedral clay minerals from first principles molecular dynamics simulations. Geochim. Cosmochim. Acta 2014, 140, 410-417.

(53) Liu, X.; Lu, X.; Cheng, J.; Sprik, M.; Wang, R. Temperature dependence of interfacial structures and acidity of clay edge surfaces. Geochimica et Cosmochimica Acta 2015, $160,91-99$.

(54) Liu, X.; Lu, X.; Sprik, M.; Cheng, J.; Meijer, E. J.; Wang, R. Acidity of edge surface sites of montmorillonite and kaolinite. Geochim. Cosmochim. Acta 2013, 117, 180-190.

(55) Liu, X. D.; Lu, X. C.; Meijer, E. J.; Wang, R. C.; Zhou, H. Q. Atomic-scale structures of interfaces between phyllosilicate edges and water. Geochim. Cosmochim. Acta 2012, 81, $56-68$. 
(56) Liu, X. D.; Lu, X. C.; Wang, R. C.; Meijer, E. J.; Zhou, H. Q.; He, H. P. Atomic scale structures of interfaces between kaolinite edges and water. Geochim. Cosmochim. Acta 2012, 92, 233-242.

(57) Tazi, S.; Rotenberg, B.; Salanne, M.; Sprik, M.; Sulpizi, M. Absolute acidity of clay edge sites from ab-initio simulations. Geochim. Cosmochim. Acta 2012, 94, 1-11. phyllosilicate edge surface structures and dissolution mechanisms. Am. Mineral. 2001, $86,411-423$.

(59) Bleam, W. F.; Welhouse, G. J.; Janowiak, M. A. The surface Coulomb energy and proton Coulomb potentials of pyrophyllite $\{010\},\{110\},\{100\}$, and $\{130\}$ edges. Clays Clay Miner. 1993, 41, 305-316.

(60) Churakov, S. V. Ab initio study of sorption on pyrophyllite: Structure and acidity of the edge sites. J. Phys. Chem. B 2006, 110, 4135-4146.

(61) Newton, A. G.; Kwon, K. D.; Cheong, D.-K. Edge structure of montmorillonite from atomistic simulations. Minerals 2016, 6, 25.

(62) Newton, A. G.; Sposito, G. Molecular dynamics simulations of pyrophyllite edge surfaces: structure, surface energies, and solvent accessibility. Clays Clay Miner. 2015, 63, 277-289.

(63) White, G. N.; Zelazny, L. W. Analysis and implications of the edge structure of dioctahedral phyllosilicates. Clays Clay Miner. 1988, 36, 141-146.

(64) Kwon, K. D.; Newton, A. G. Structure and stability of pyrophyllite edge surfaces: Effect of temperature and water chemical potential. Geochim. Cosmochim. Acta 2016, 190, $100-114$.

(65) Hadi, J.; Tournassat, C.; Ignatiadis, I.; Greneche, J.-M.; Charlet, L. Modelling CEC variations versus structural iron reduction levels in dioctahedral smectites. Existing approaches, new data and model refinements. J. Colloid Interface Sci. 2013, 407, $397-$ 409.

(66) Lammers, L. N.; Bourg, I. C.; Okumurad, M.; Kolluria, K.; Sposito, G.; Machidad, M. Molecular dynamics simulations of cesium adsorption on illite nanoparticles. J. Colloid Interface Sci. 2016, submitted,

(67) Viani, A.; Gualtieri, A. F.; Artioli, G. The nature of disorder in montmorillonite by simulation of X-ray powder patterns. Am. Mineral. 2002, 87, 966-975.

(68) Michot, L. J.; Villiéras, F. Chapter 2.10 - Surface Area and Porosity; In Handbook of Clay Science; Bergaya, F.; Lagaly, G., Eds.; Developments in Clay Science; Elsevier, 2013; Vol. 5, pp. 319-332.

(69) Srodon, J.; McCarty, D. K. Surface area and layer charge of smectite from CEC and EGME/ $\mathrm{H}_{2} \mathrm{O}-$ retention measurements. Clays Clay Miner. 2008, 56, 155-174.

(70) Tournassat, C.; Appelo, C. A. J. Modelling approaches for anion-exclusion in compacted Na-bentonite. Geochim. Cosmochim. Acta 2011, 75, 3698-3710.

(71) Cadene, A.; Durand-Vidal, S.; Turq, P.; Brendle, J. Study of individual Namontmorillonite particles size, morphology, and apparent charge. J. Colloid Interface Sci. 2005, 285, 719-730.

(72) Nadeau, P. H. The physical dimensions of fundamental clay particles. Clay Miner. 1985, 20, 499-514. 
608

609

610

611

612

613

614

615

616

617

618

619

620

621

622

623

624

625

626

627

628

629

630

631

632

633

634

635

636

637

638

639

640

641

642

643

644

645

646

647

648

649

650

651

652

653

(73) Tournassat, C.; Neaman, A.; Villiéras, F.; Bosbach, D.; Charlet, L. Nanomorphology of montmorillonite particles: Estimation of the clay edge sorption site density by lowpressure gas adsorption and AFM observations. Am. Mineral. 2003, 88, 1989-1995.

(74) Reinholdt, M. X.; Hubert, F.; Faurel, M.; Tertre, E.; Razafitianamaharavo, A.; Francius, G.; Prêt, D.; Petit, S.; Béré, E.; Pelletier, M.; Ferrage, E. Morphological properties of vermiculite particles in size-selected fractions obtained by sonication. Appl. Clay Sci. 2013, 77, 18-32.

(75) Bradbury, M. H.; Baeyens, B. A mechanistic description of Ni and Zn sorption on Namontmorillonite. Part II: modeling. J. Contam. Hydrol. 1997, 27, 223-248.

(76) Grambow, B.; Fattahi, M.; Montavon, G.; Moisan, C.; Giffaut, E. Sorption of Cs, Ni, Pb, $\mathrm{Eu}(\mathrm{III}), \mathrm{Am}(\mathrm{III}), \mathrm{Cm}, \mathrm{Ac}(\mathrm{III}), \mathrm{Tc}(\mathrm{IV}), \mathrm{Th}, \mathrm{Zr}$, and U(VI) on MX80 bentonite: an experimental approach to assess model uncertainty. Radiochim. Acta 2006, 94, 627-636.

(77) Montavon, G.; Alhajji, E.; Grambow, B. Study of the interaction of $\mathrm{Ni}^{2+}$ and $\mathrm{Cs}^{+}$on MX80 bentonite; Effect of compaction using the "capillary method. Environ. Sci. Technol. 2006, 40, 4672-4679.

(78) Tertre, E.; Beaucaire, C.; Coreau, N.; Juery, A. Modelling Zn(II) sorption onto clayey sediments using a multi-site ion-exchange model. Appl. Geochem. 2009, 24, 1852-1861.

(79) Wolthers, M.; Charlet, L.; Tournassat, C. Reactivity of bentonite. An additive model applied to uranyl sorption; In Surface complexation modelling; Lützenkirchen, J., Ed.; Elsevier, 2006.

(80) Avena, M. J. Acid-base behavior of clay surfaces in aqueous media. Encyclopedia of surface and colloid science 2002, 37-63.

(81) Avena, M. J.; Mariscal, M. M.; De Pauli, C. P. Proton binding at clay surfaces in water. Appl. Clay Sci. 2003, 24, 3-9.

(82) Barbier, F.; Duc, G.; Petit-Ramel, M. Adsorption of lead and cadmium ions from aqueous solution to the montmorillonite/water interface. Colloid. Surface. A. 2000, 166, $153-159$.

(83) Charlet, L.; Schindler, P. W.; Spadini, L.; Furrer, G.; Zysset, M. Cation adsorption on oxides and clays: the aluminum case. Aquatic Science 1993, 55, 1015-1621.

(84) Ikhsan, J.; Wells, J. D.; Johnson, B. B.; Angove, M. J. Surface complexation modeling of the sorption of Zn(II) by montmorillonite. Colloid. Surface. A. 2005, 252, 33-41.

(85) Kowal-Fouchard, A.; Drot, R.; Simoni, E.; Ehrhardt, J. J. Use of spectroscopic techniques for uranium(VI)/montmorillonite interaction modeling. Env. Sci. Tech. 2004, 38, 1399-1407.

(86) Madrid, L.; Diaz-Barrentios, E. Description of titration curves of mixed materials with variable and permanent surface charge by amathematical model. 1. Theory. 2. Application to mixtures of lepidocrocite and montmorillonite. Journal of Soil Science 1988, 39, 215-225.

(87) Marcussen, H.; Holm, P. E.; Strobel, B. W.; Hansen, H. C. B. Nickel sorption to goethite and montmorillonite in presence of citrate. Env. Sci. Tech. 2009, 43, 1122-1127.

(88) Stadler, M.; Schindler, P. W. Modeling of $\mathrm{H}^{+}$and $\mathrm{Cu}^{2+}$ adsorption on calciummontmorillonite. Clays Clay Miner. 1993, 41, 288-296.

(89) Tombácz, E.; Nyilas, T.; Libor, Z.; Csanaki, C. Surface charge heterogeneity and aggregation of clay lamellae in aqueous suspensions; In Progress in Colloid and Polymer Science: From Colloids to Nanotechnology; Kremer, F.; Lagaly, G., Eds.; Springer, 2004; Vol. 125, pp. 206-215. 
654

655

656

657

658

659

660

661

662

663

664

665

666

667

668

669

670

671

672

673

674

675

676

677

678

679

680

681

682

683

684

685

686

687

688

689

690

691

692

693

694

695

696

697

698

(90) Wanner, H.; Albinson, Y.; Karnland, O.; Wieland, E.; Wersin, P.; Charlet, L. The acid/base chemistry of montmorillonite. Radiochim. Acta 1994, 66/67, 157-162.

(91) Zachara, J. M.; Smith, S. C. Edge complexation reactions of cadmium on specimen and soil-derived smectite. Soil Sci. Soc. Am. J. 1994, 58, 762-769.

(92) Chang, F. R. C.; Sposito, G. The electrical double layer of a disked-shaped clay mineral particle: effect of electrolyte properties and surface charge density. J. Colloid Interface Sci. 1996, 178, 555-564.

(93) Chang, F. R. C.; Sposito, G. The electrical double layer of a disked-shaped clay mineral particle: effect of particle size. J. Colloid Interface Sci. 1994, 163, 19-27.

(94) Secor, R. B.; Radke, C. J. Spillover of the diffuse double layer on montmorillonite particles. J. Colloid Interface Sci. 1985, 103, 237-244.

(95) Henderson, D.; Boda, D. Insights from theory and simulation on the electrical double layer. Phys. Chem. Chem. Phys. 2009, 11, 3822-3830.

(96) Tinnacher, R. M.; Holmboe, M.; Tournassat, C.; Bourg, I. C.; Davis, J. A. Ion adsorption and diffusion in smectite: molecular, pore, and continuum scale views. Geochim. Cosmochim. Acta 2016, 177, 130-149.

(97) Parkhurst, D. L.; Appelo, C. A. J. Description of input and examples for PHREEQC Version 3- a computer program for speciation,batch-reaction, one-dimensional transport, and inverse geochemical calculations; U.S. Geological Survey Techniques and Methods, book 6, chap. A43, 497 p., available at http://pubs.usgs.gov/tm/06/a43/, 2013.

(98) Méring, J. On the hydration of montmorillonite. Transaction of Faraday Society 1946, 42, B205-B219.

(99) Norrish, K. The swelling of montmorillonite. Faraday Discuss. Chem. Soc. 1954, 18, 120-134.

(100) Segad, M.; Hanski, S.; Olsson, U.; Ruokolainen, J.; Åkesson, T.; Jönsson, B. Microstructural and swelling properties of $\mathrm{Ca}$ and $\mathrm{Na}$ montmorillonite:(in situ) observations with cryo-TEM and SAXS. J. Phys. Chem. C. 2012, 116, 7596-7601.

(101) Sposito, G. The diffuse-ion swarm near smectite particles suspended in 1:1 electrolyte solutions: modified Gouy-Chapman theory and quasicrystal formation; In Clay water interface and its rheological implications; Güven, N.; Pollastro, R. M., Eds.; Clay minerals society, 1992; Vol. 4, pp. 127-156.

(102) Leung, K.; Criscenti, L. J. Predicting the acidity constant of a goethite hydroxyl group from first principles. J. Phys.: Condens. Matter 2012, 24, 124105.

(103) Leung, K.; Nielsen, I. M.; Criscenti, L. J. Elucidating the bimodal acid-base behavior of the water-silica interface from first principles. J. Am. Chem. Soc. 2009, 131, 1835818365.

(104) Sulpizi, M.; Gaigeot, M.-P.; Sprik, M. The silica-water interface: how the silanols determine the surface acidity and modulate the water properties. J. Chem. Theory Comput. 2012, 8, 1037-1047.

(105) Helmy, A.; Ferreiro, E.; De Bussetti, S. Cation exchange capacity and condition of zero charge of hydroxy-A1 montmorillonite. Clays Clay Miner. 1994, 42, 444-450.

(106) Thomas, F.; Michot, L. J.; Vantelon, D.; Montarges, E.; Prelot, B.; Cruchaudet, M.; Delon, J. F. Layer charge and electrophoretic mobility of smectites. Colloid. Surface. A. 1999, 159, 351-358. 
699 (107) Hiemstra, T.; Van Riemsdijk, W. H. On the relationship between charge distribution, surface hydration, and the structure of the interface of metal hydroxides. J. Colloid Interface Sci. 2006, 301, 1-18.

702

703

704

705

706

707

708

709

710

(108) Kulik, D. A. Thermodynamic concepts in modeling sorption at the mineral-water interface. Rev. Mineral. Geochem. 2009, 70, 125-180.

(109) Fletcher, P.; Sposito, G. The chemical modeling of clay/electrolyte interactions for montmorillonite. Clay Miner. 1989, 24, 375-391.

(110) Drits, V. A.; Zviagina, B. B. Trans-vacant and cis-vacant 2:1 layer silicates: structural features, identification, and occurrence. Clays Clay Miner. 2009, 57, 405-415.

(111) Tsipursky, S. I.; Drits, V. A. The distribution of octahedral cations in the 2:1 layers of dioctahedral smectites studied by oblique-texture electron diffraction. Clay Miner. 1984, 711 19, 177-193. 

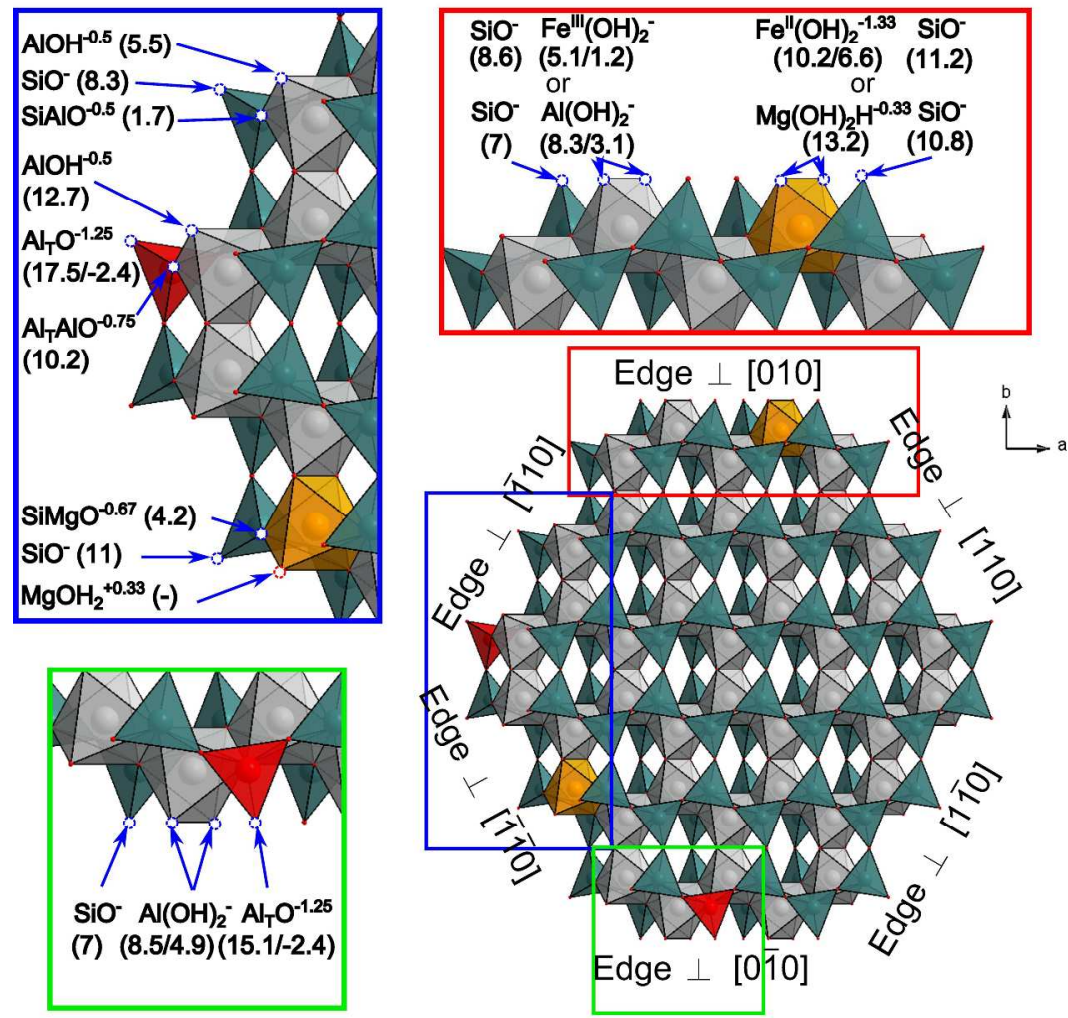

Figure 1

$297 \times 420 \mathrm{~mm}(300 \times 300$ DPI $)$ 

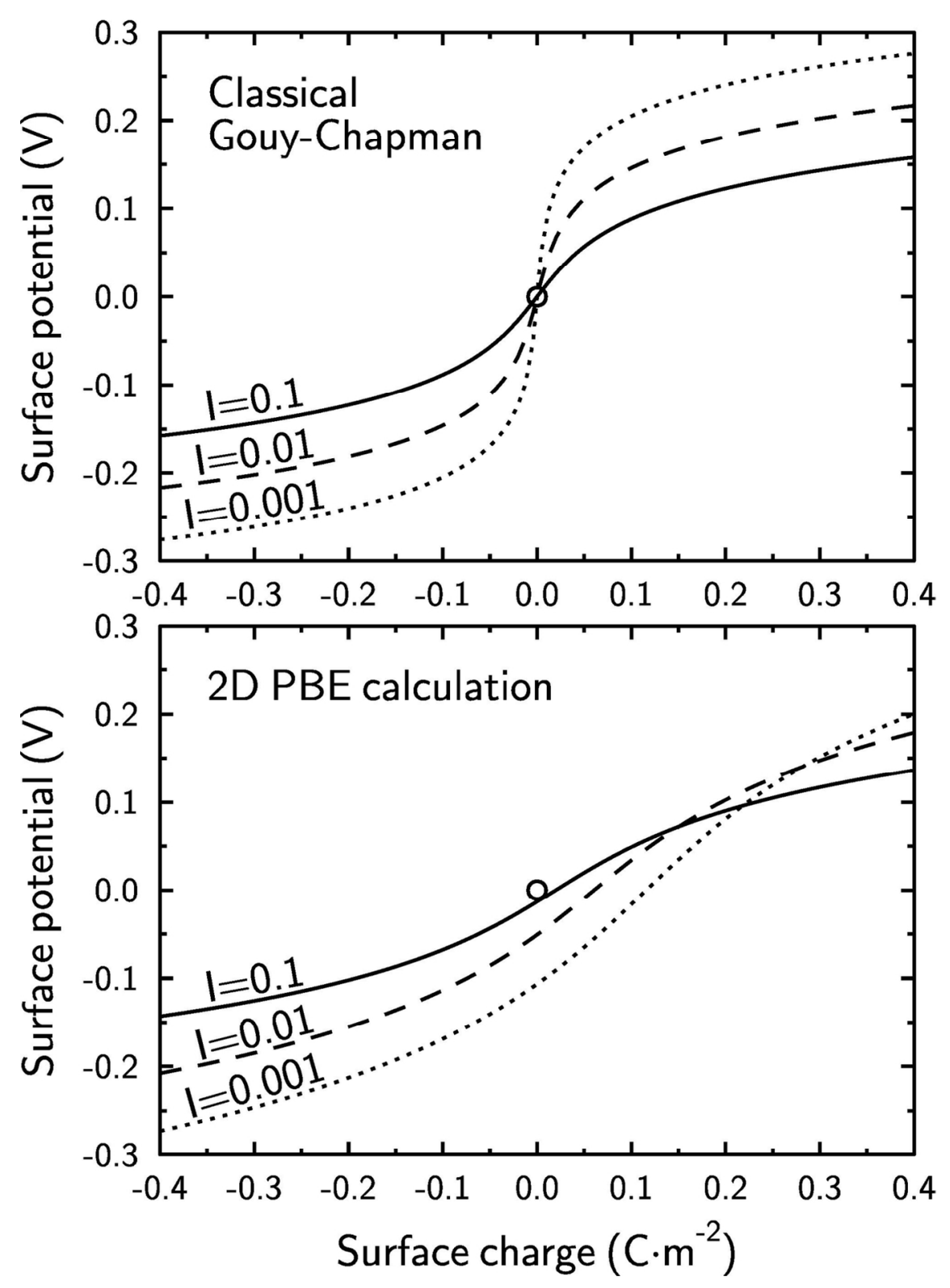

Figure 2

$117 \times 161 \mathrm{~mm}(300 \times 300 \mathrm{DPI})$ 

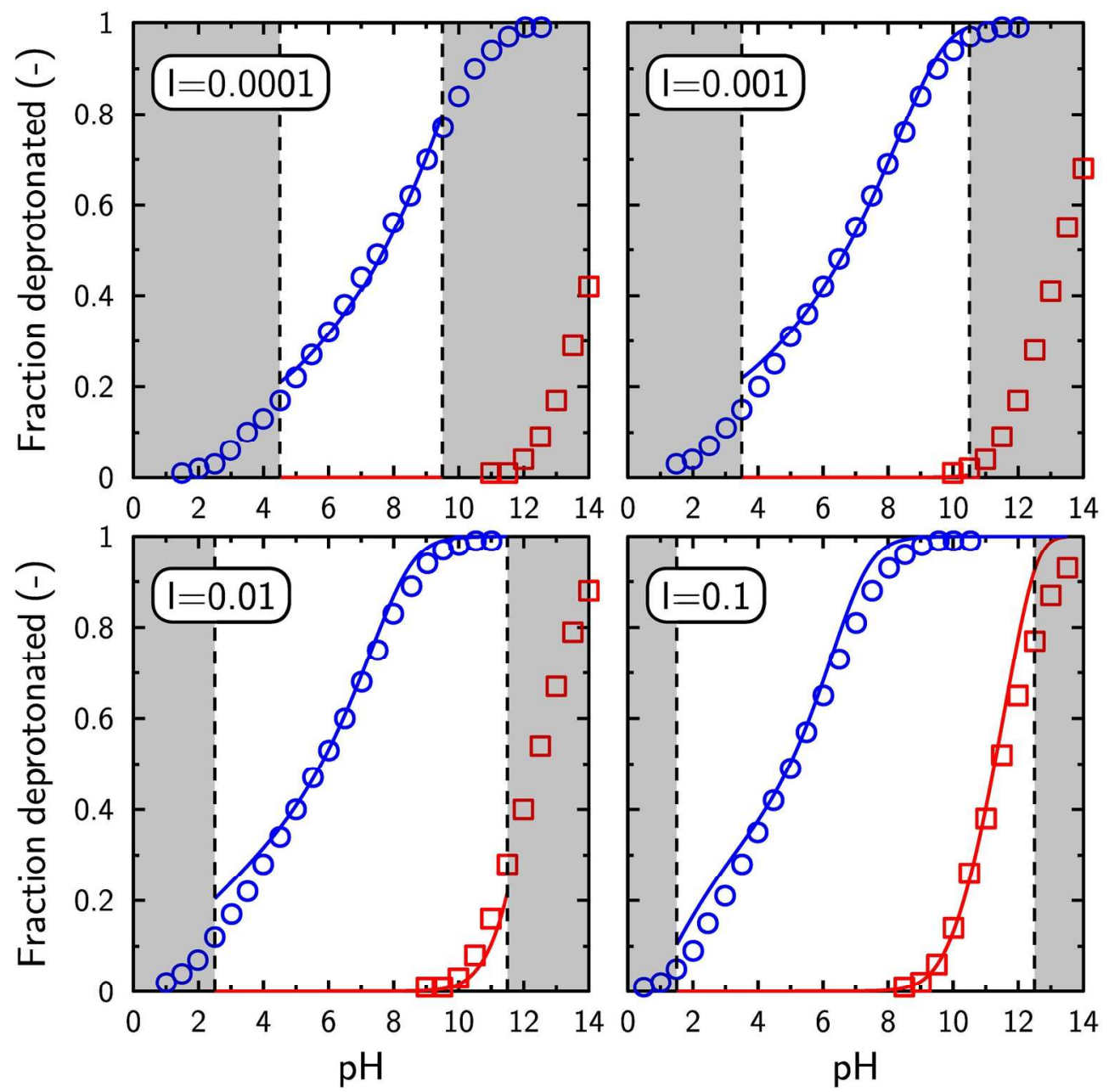

Figure 3

$166 \times 163 \mathrm{~mm}(300 \times 300$ DPI $)$ 

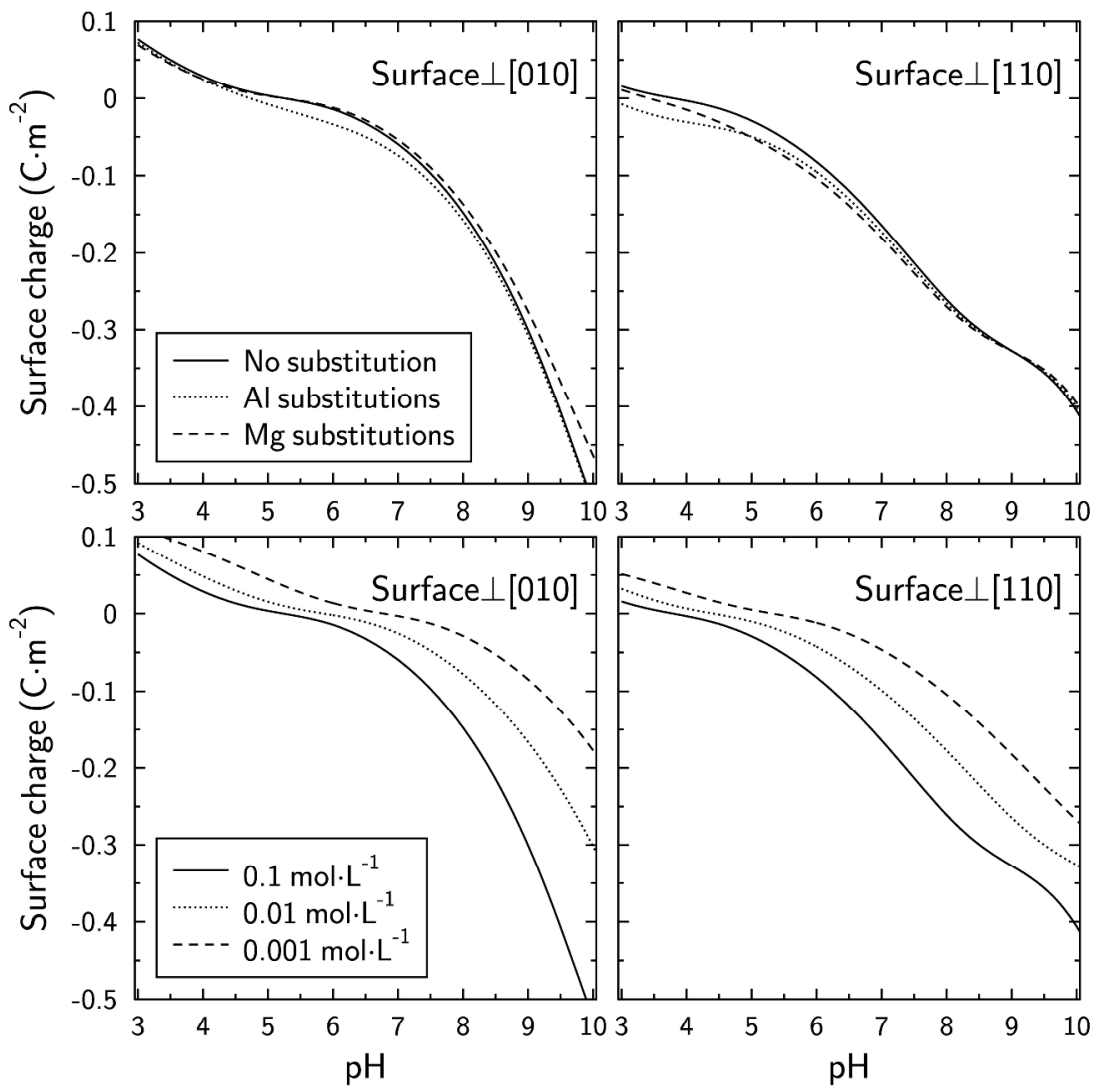

Figure 4

297x420mm (300 x 300 DPI) 


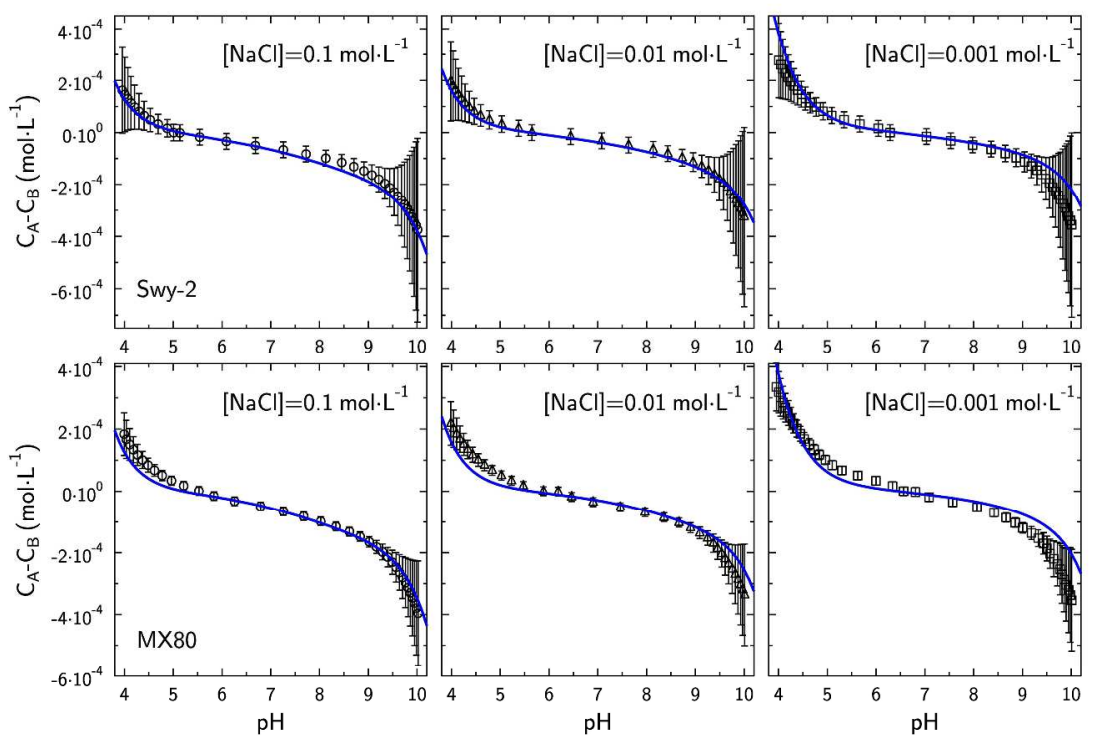

Figure 5

$297 \times 420 \mathrm{~mm}(300 \times 300$ DPI $)$ 


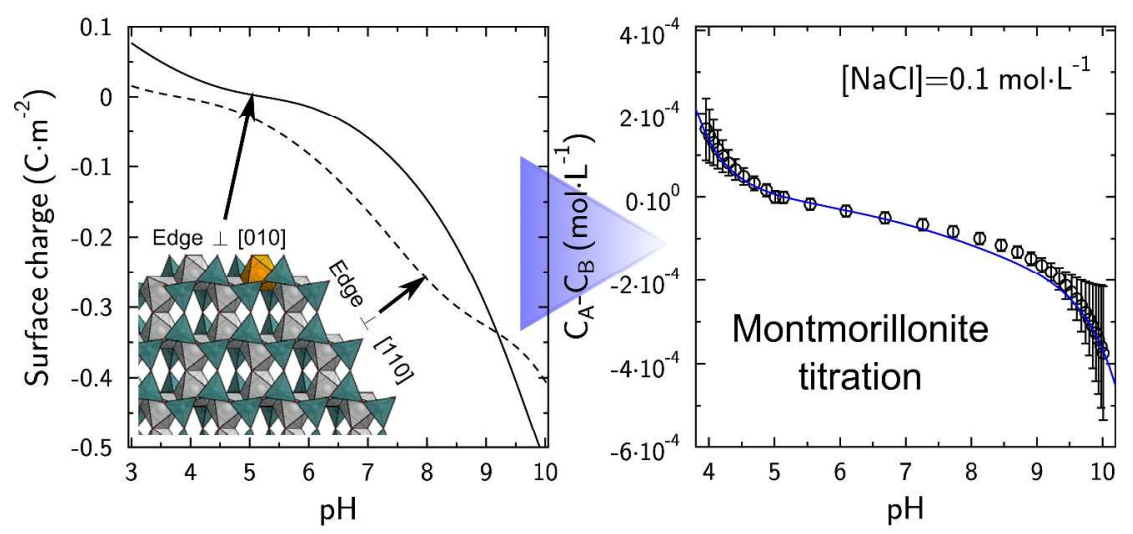

TOC

$297 \times 420 \mathrm{~mm}(300 \times 300 \mathrm{DPI})$ 